\title{
How Significant are Low-Level Flow Patterns in Tropical Cyclone Genesis over the Western North Pacific?
}

\author{
RYUJI YOSHIDA \\ CIRES, University of Colorado Boulder, and NOAA/Earth System Research Laboratory, Boulder, Colorado, and RIKEN \\ Center for Computational Science, and Research Center for Urban Safety and Security, Kobe University, Kobe, Japan \\ HIRONORI FUDEYASU \\ Yokohama National University, Yokohama, Japan
}

(Manuscript received 28 January 2019, in final form 18 October 2019)

\begin{abstract}
The low-level flow pattern characteristics of the tropical cyclone genesis (TCG) environment over the western North Pacific (WNP) were investigated not only for the periods during which TCG occurred, but also for the periods during which no TCG occurred. The flow patterns investigated were the shear line (SL), confluence region (CR), and easterly wave (EW) patterns. Although these flow patterns are recognized as favorable environmental conditions for TCG, their general characteristics, such as the climatological horizontal distribution, have not been previously investigated and there has been no comparison of the significance of the TCG cases to the climatological mean. We examined flow patterns using flow pattern indices defined by the modified semiobjective analysis method. SL and CR were broadly distributed over the WNP east of the Philippines during the boreal summer season. There was a peak in the EW from summer to autumn and it was distributed in a band running in an east-west direction at a lower latitude. Flow pattern indices of all three flow patterns gradually intensified until the TCG date was reached. The SL and EW indices became more intense compared to the climatological mean one day before the TCG, while that of the CR did not exceed the climatological mean. TCG occurred at the eastern edge of the area with a high genesis potential index and relative humidity and a weak vertical shear over flow patterns. This determination of the general characteristics of favorable flow pattern conditions improves our understanding of the TCG process.
\end{abstract}

\section{Introduction}

Tropical cyclones result in natural disasters given their heavy rainfall and strong winds, and storm surge. Many studies of tropical cyclone track, structure, and intensity have been conducted to improve forecast skills. For countries with long coastlines, the grace period before a tropical cyclone reaches land tends to be short. Therefore, understanding tropical cyclone genesis (TCG) and developing a forecasting system for genesis is essential for the prevention and mitigation of natural disasters resulting from tropical cyclones.

The general environmental conditions of TCG are relatively well understood. Gray $(1968,1998)$ reported a set of suitable environmental conditions by averaging the data of all basins where tropical cyclones are observed. It will be noted that favorable conditions and

Corresponding author: Ryuji Yoshida, ryuji.yoshida@noaa.gov indices developed from them do not identify precursor wave and wavelike disturbances on the synoptic scale, and their favorable mesoalpha-scale subregions for TCG. Therefore, the statistical significance of methods based on circulation patterns alone is relatively low. The set of suitable environmental conditions were a high sea surface temperature (SST), conditional instability of stratification, convergence in the low-level troposphere and divergence in the upper-level troposphere, cyclonic circulation in the low-level troposphere, and a weak deep vertical shear of horizontal wind. Based on Gray (1968, 1998), several genesis parameter indices have been suggested to study the general characteristics of the TCG environment (Gray 1998; Zehr 1992; and Emanuel and Nolan 2004). DeMaria et al. (2001) developed a genesis parameter to apply to TCG forecasts using vertical shear of horizontal wind, stability of stratification, and midlevel moisture. Schumacher et al. (2009) updated the genesis parameter by adding several variables (i.e., land coverage, 
low-level circulation, and low-level divergence) for use in short-range TCG forecasting. The performance was acceptable but the significance remained low, as in previous studies.

In terms of the mean circulation pattern, the Asian the monsoon trough, monsoon westerly wind and trade easterly wind are general characteristics of the boreal summer over the WNP (Gray 1968, 1998; Zehr 1992; Yanai 1961, 1968; Holland 1995). Statistical analysis can break down the TCG environment into several categories (Ritchie and Holland 1999; Lee et al. 2008). Ritchie and Holland (1999) visually categorized TCG cases into five patterns of low-level flow features: a monsoon shear line (SL) pattern, monsoon confluence region $(\mathrm{CR})$ pattern, monsoon gyre pattern, easterly wave (EW) pattern, and Rossby energy dispersion from a preexisting tropical cyclone. They reported that the monsoon SL, monsoon CR, and EW patterns were the most frequent flow patterns over the WNP. The environment of the flow pattern also has an influence on the characteristics (e.g., strength and track) of the tropical cyclones after the TCG (Fudeyasu and Yoshida 2018). Yoshida and Ishikawa (2013) developed a semiobjective analysis method to categorize the five flow patterns for a longterm analysis, with a stable reliable criterion. Although the classification flow patterns were based on the categorization of Ritchie and Holland (1999), the analysis method can automatically and reasonably categorize and not rely on the human senses. They analyzed more than 900 TCG cases occurring over a 30-yr period from 1979 to 2008 and found that approximately $70 \%$ could be explained by three flow patterns: the monsoon SL, monsoon CR, and EW patterns. This is consistent with that found in Ritchie and Holland (1999); the semiobjective analysis method can reproduce the subjective analysis. However, forecasting of TCG is still a difficult challenge despite many efforts on understanding TCG.

One possible reason for the difficulty in forecasting is the differences among the genesis pathways (Wang et al. 2018). The genesis pathway determines the TCG type according to its energy source. The TCG probabilities were investigated for each pathway and it was found that the tropical transition pathways had a lower probability than that of the other pathways. Similar differences in TCG probability have been found in different flow patterns over the western North Pacific (WNP). Another reason for the low significance of circulation patterns and environment indices is that the wave and wavelike precursors to TCG are not identified. These disturbances depend on, but do not necessarily accompany, the circulation patterns and environment factors required for the disturbances.
Similarly, the synoptic-scale wave precursors do not guarantee that favorable mesoalpha-scale conditions exist within the disturbances. Several studies have worked in this direction by emphasizing that TCG is not merely about precursor circulation patterns but the wave or wavelike disturbances that arise on these patterns. Influences on TCG by planetary and synopticscale waves on TCG has been investigated (Molinari and Vollaro 2000; Li 2006; Li and Fu 2006; Li et al 2006). Schreck et al. (2011; 2012) attempted to explain a development process of the precursor emerging from various equatorial waves. A relationship between the MaddenJulian oscillation (MJO; Madden and Julian 1994) and TCG has been also studied (Frank and Roundy 2006; Camargo et al. 2009). Molinari et al. (2007) reported a developing precursor in an equatorial Rossby wave packet, and Dunkerton et al. (2009) suggested that the precursor development tends to occur near a quasi-closed pouch that is bound by the outer manifold and includes cyclonic circulation within the closed streamline. The pouch maintains a suitable environment along the migration of a tropical disturbance, which is referred to as the marsupial paradigm. Wang et al. (2012) has shown the applicability of the marsupial paradigm. These studies in terms of the equatorial waves can enhanced understanding of the TCG process related with the dynamics of tropical atmosphere. Our study is intended to extend and refine the description of circulation patterns favorable to TCG, while leaving for further study the relationships between these patterns and variety of disturbance types that precede genesis.

Attempts to understand or to forecast TCG from the mean circulation pattern of the precursor regardless of basin may have low statistical significance because the associate precursor disturbances and their dependence on circulation pattern have not been identified, nor their contribution to enhanced understanding and forecast skill. The understanding in terms of low-level flow patterns to categorize TCG cases still has usefulness because of intuitiveness. The flow pattern can be recognized easily on weather maps. An improvement of the analysis method is necessary to acquire more usefulness, because flow pattern characteristics have been investigated only for periods during which TCG occurred. The general characteristics of lowlevel flow patterns, regardless of TCG events, have not yet been determined and there may be differences between genesis and nongenesis cases. These differences should be studied to understand how a tropical disturbance can develop into a tropical cyclone. Zehr (1992) found that a strong vertical shear of horizontal wind and/or low levels of moisture led to the dissipation 
of a tropical disturbance. Tuleya (1991) investigated the sensitivity of vertical shear strength through numerical simulations, with a strong vertical shear found to be unsuitable for TCG. In numerical simulations, a nondeveloped tropical disturbance develops into a tropical cyclone with a continuous large-scale environment that contains a large amount of moisture (Yoshida et al. 2017).

In this study, low-level flow pattern climatological characteristics over the WNP were investigated to better understand the flow patterns during genesis periods. The climatological characteristics included features of nongenesis periods. Because there are only a few days during which TCG is observed each year, the mean value of all days in 1 year can be assumed to represent the state of nongenesis days (i.e., days in which a TCG case was not observed). Therefore, we could determine the significance of low-level flow patterns by comparison to climatological mean values. However, the semiobjective analysis method of low-level flow pattern categorization suggested by Yoshida and Ishikawa (2013) is dependent on cyclone track data to determine the genesis location and time. We modified the semiobjective analysis method to fit the aims of this study. In this study, we focused only on the frequent types of low-level flow patterns over the WNP to ensure statistical significance: the SL, CR, and EW patterns.

We explain the details of the modification of the semiobjective analysis method and the utilized data in section 2. The general characteristics of the analysis are described in section 3 and details of the seasonal and interannual variabilities are presented in section 4 . We discuss the differences in environmental conditions between the genesis and nongenesis periods in section 5 . In section 6 , a summary of the study is provided.

\section{Data and methodology}

\section{a. Modified semiobjective categorization method}

Yoshida and Ishikawa (2013) suggested the use of TCG contribution scores in a categorization procedure as a means to automatically examine the contribution of flow patterns for a TCG case. This is a semiobjective categorization method compatible with the subjective categorization of Ritchie and Holland (1999), which does not guarantee a perfect matching with the categorization of Ritchie and Holland (1999) on a caseby-case basis, but was tested for statistical consistency of the categorization rate for each flow pattern. The contribution scores for the SL, CR, and EW patterns consist of an intensity term, distance term, and artificial parameters. The artificial parameters were used to tune the score distribution in a two-dimensional space of the intensity and distance terms. They were calculated using the zonal and meridional wind components at an $850 \mathrm{hPa}$ height. The categorization procedure had three steps as follows: 1) search the flow patterns around the TCG location using a detection algorithm, 2) calculate the contribution score of the TCG case, and 3) determine the major flow pattern of the TCG case by comparing scores. The calculation of contribution scores was conducted for every TCG case before moving to the third step, and the raw scores of each flow pattern were normalized by the maximum and minimum values of the dataset. We then obtained the normalized score of each flow pattern (i.e., from 0 to 1 ), which could be compared to that of the other flow patterns. Each step was conducted for each flow pattern for all TCG cases in the best track data. Although this enabled an examination of the flow pattern for a specific TCG case, it could not be applied to investigations of nongenesis periods given the lack of track data. To address the flow pattern climatological characteristics during a nongenesis period, we modified the definition of the TCG contribution scores for the SL, CR, and EW patterns as follows:

$$
\begin{aligned}
\operatorname{scr}_{\mathrm{SL}} & =\operatorname{ave}\left(\frac{\partial u}{\partial y}\right) \exp \left(-A \text { dist }_{\text {min_sL }}\right), \\
\mathrm{scr}_{\mathrm{CR}} & =\operatorname{ave}\left(\frac{\partial u}{\partial x}\right) \exp \left(-A \text { dist }_{\text {min_CR }}\right), \\
\mathrm{scr}_{\mathrm{EW}} & =\operatorname{ave}\left(\frac{\partial v}{\partial x}\right) \exp \left(-A \text { dist }_{\text {min_EW }}\right),
\end{aligned}
$$

where $u$ and $v$ are the horizontal wind velocity at $850 \mathrm{hPa}$ height for the zonal component and meridional component, respectively; $x$ and $y$ are the horizontal axes in longitudinal direction and latitudinal direction in the input reanalysis data, respectively; $A$ is a tuning parameter to adjust the distance range for the exponential function that was empirically decided as $A=10^{-5}$ for the SL and CR patterns and $A=10^{-2}$ for the EW pattern; the operator ave() is the average for all grids detected as a flow pattern by the detection algorithm; and dist $_{\text {min }}$ is the minimum distance between a specific grid point where the score is calculated and the grid point detected the flow pattern. Therefore, Eqs. (1)-(3) consist of the multiplication of an intensity term [e.g., ave $(\partial u / \partial y)$ in Eq. (1)] and a distance term [e.g., $\exp (-A$ dist $_{\text {min_sL }}$ ) in Eq. (1)]. This configuration assumes that a higher flow pattern intensity can provide a greater contribution to the arrangement of the TCG environment and a shorter distance can have a larger impact on the TCG environment. The essential flow structure for 
the SL, CR, and EW patterns is a line of meridional shear of zonal wind, a convergence of the zonal wind, and a synoptic-scale trough, respectively. The SL pattern is identified by the meridional shear of the zonal wind $(\partial u / \partial y), \mathrm{CR}$ by the convergence of the zonal wind $(\partial u / \partial x)$, and EW by the vorticity of the meridional wind $(\partial v / \partial x)$. The definitions of the contribution scores for each flow pattern are not empirically derived, but are a

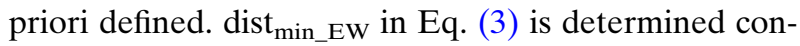
sidering the propagation of the EW pattern. Although the SL and CR patterns are nearly stationary during a short time period of less than a week, the EW pattern propagates westward even during a short time period. Following Yoshida and Ishikawa (2013), the propagation speed was assumed to be the same as the averaged easterly wind speed near the EW pattern and the time scale was set as $69 \mathrm{~h}$.

The final form of flow pattern indices $\left(\mathrm{FPI}_{\mathrm{pat}}\right)$ is defined as follows:

$$
\mathrm{FPI}_{\mathrm{pat}}=\frac{\mathrm{scr}_{\mathrm{pat}}-\operatorname{mean}\left[\mathrm{scr}_{\mathrm{pat}}\right]}{\operatorname{stddev}\left[\mathrm{scr}_{\mathrm{pat}}\right]},
$$

which is normalized by a climatological mean of score (indicated by mean[ ]) and a climatological standard deviation of score (indicated by stddev[]). The subscript "pat" is an abbreviation of the SL, CR, or EW patterns. In the new definition, we used the climatological mean and the standard deviation instead of the maximum and the minimum values, for score normalization. The climatological values for each flow pattern were calculated for all days in the 38-yr period from 1979 to 2016 and for all grid points at once. Therefore, the normalized flow pattern index (FPI) indicates how significant the flow pattern is compared to the climatology. Furthermore, the artificial parameters used in the original definition of Yoshida and Ishikawa (2013) were eliminated here. Because the FPI was normalized against the climatological values, the score distribution for the distance and strength terms was not considered. Hereafter, we refer to the flow pattern indices in association with the relevant pattern (e.g., "FPI-SL").

During the first step of the score calculation, the flow patterns around the TCG location were identified based on information obtained from the best track data in Yoshida and Ishikawa (2013). In the current study, we identified the flow patterns at every location among the grid points of the input data inside the analysis region instead of using the best track data. The analysis region for flow pattern detection was from $100^{\circ} \mathrm{E}$ to $170^{\circ} \mathrm{W}$ longitude and from $5^{\circ} \mathrm{S}$ to $35^{\circ} \mathrm{N}$ latitude. The analysis region for the climatological value calculation was from $110^{\circ} \mathrm{E}$ to $180^{\circ}$ longitude and from $5^{\circ}$ to $25^{\circ} \mathrm{N}$ latitude.
The analysis region for detection had a sufficient margin to freely detect the shape of the flow patterns. The flow patterns were searched around the grid point calculating the scores based on a flow shape of the $850 \mathrm{hPa}$ flow field. For example, the SL pattern flow shape is detected as a series of grid points where an easterly wind is found to the north and a westerly wind to the south. This flow pattern search was conducted via the automatic detection algorithm for all three flow patterns. The automatic detection algorithm used in this study was the same as that used in Yoshida and Ishikawa (2013), except for the detection limit settings (for details of the algorithm, see section 3 in Yoshida and Ishikawa 2013). The detection limit is the maximum distance between the calculation grid point and the flow pattern, and the settings were $1500 \mathrm{~km}$ for SL, $1500 \mathrm{~km}$ for CR, and approximately $2200 \mathrm{~km}\left(20^{\circ}\right)$ for the EW patterns. This detection limit is not an area averaging radius. No area averaging was applied for the score at calculation of Eqs. (1)-(4). The flow pattern detection and the calculation of the contribution scores were performed for all grid points in the analysis region at all time steps during the analysis period. The climatological mean and standard deviation were calculated for every flow pattern. Then, the FPI calculation was repeated for every flow pattern for all grid points for all time steps. Finally, we obtained the FPI grid point values for each flow pattern at every time step over the grid points in the analysis region.

A traditional genesis potential index (GPI) of Emanuel and Nolan (2004) was used in this study to determine the general condition of the TCG environment because investigating climatology of TCG is our purpose. Although the GPI has less skill for TCG forecasting than the newly proposed genesis parameters, the GPI has been developed using a statistical approach over a long period, which has proven to be useful in investigating climatological and interannual variations of TCG environment, for example relationships with the El Niño-Southern Oscillation (Camargo et al. 2007), modulations by the MJO (Camargo et al. 2009), and for future climate changes (Emanuel 2013). GPI was defined as GPI $=\left|10^{5} \eta\right|^{3 / 2}(H / 50)^{3}\left(V_{\text {pot }} / 70\right)^{3}(1+0.1 \mathrm{VS})^{-2}$ following Emanuel and Nolan (2004), where $\eta$ is the absolute vorticity at $850 \mathrm{hPa}$ height, $H$ is the relative humidity (RH) at $700 \mathrm{hPa}$ height, and $V$ pot is the potential intensity calculated using a FORTRAN routine provided by Dr. Emanuel (http://eaps4.mit.edu/faculty/ Emanuel/products). Vertical shear of horizontal wind is defined as VS $=\sqrt{\left(\overline{u_{200}}-\overline{u_{850}}\right)^{2}+\left(\overline{v_{200}}-\overline{v_{850}}\right)^{2}}$ using horizontal wind components at $200 \mathrm{hPa}$ height and $850 \mathrm{hPa}$ height. We referred to these parameters indicating the TCG environment as genesis environment parameters. 

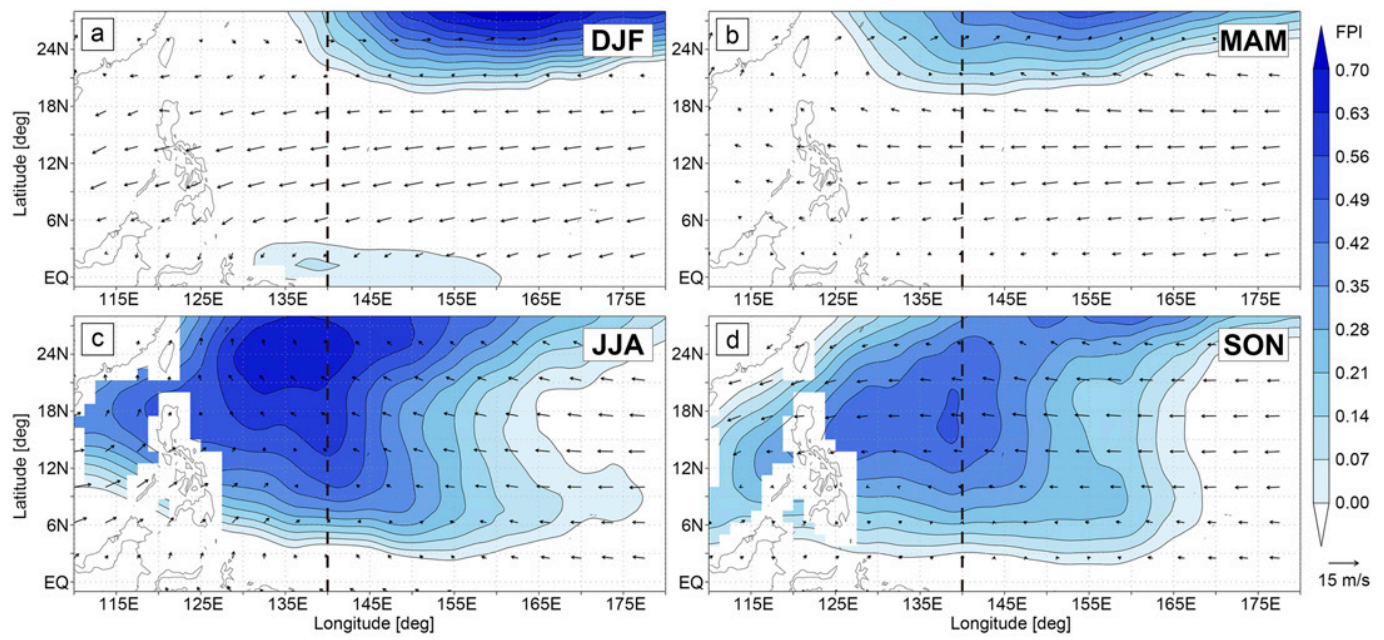

FIG. 1. Horizontal distributions of the shear line flow pattern index over the western North Pacific based on the mean values from 1979 to 2016 for (a) December-February (DJF), (b) March-May (MAM), (c) June-August (JJA), and (d) September-November (SON). Each flow pattern index is the seasonal mean value of the period. The vectors are the mean horizontal wind at $850 \mathrm{hPa}$ height over the same averaging period. Broken lines show the location of $140^{\circ} \mathrm{E}$ longitude.

\section{b. Data and analysis period}

The Japanese 55-year Reanalysis Project dataset (JRA-55; Kobayashi et al. 2015; Harada et al. 2016; details are available online at http://jra.kishou.go.jp/JRA-55/ index_en.html) was used to calculate the FPI. The JRA55 was used in the TCG categorization of Yoshida and Ishikawa (2013) type (Fudeyasu and Yoshida 2019); therefore, the applicability of this reanalysis data has already been demonstrated. To increase the accuracy of the flow pattern detection by filtering out small-scale perturbations, the input data were processed using a low- or bandpass filter. A 5-day low-pass filter was used for FPISL and FPI-CR calculation, while a 3-5-day bandpass filter was used for FPI-EW calculation. The best track data produced and archived by the Joint Typhoon Warning Center (JTWC) were also used to evaluate the significance of the flow patterns when TCG occurred. The analysis period was the 38 years from 1979 to 2016 . The number of addressed TCG cases during this period was 1110 over all seasons and 761 during the boreal summer [i.e., July-August-September-October (JASO)]. Because the focus of this study was the early TCG phase, the initial location and time of each best track record was used as the TCG location and time following Ritchie and Holland (1999) and Yoshida and Ishikawa (2013).

\section{Climatological characteristics of low-level flow patterns}

Figure 1 shows the horizontal distribution of FPI-SL over four seasons: December-January-February (DJF; winter), March-April-May (MAM; spring), June-July-August
(JJA; summer), and September-October-November (SON; autumn). The distribution of FPI-SL shows a clear seasonal variability. Large FPI-SL values are broadly distributed from $3^{\circ}$ to $25^{\circ} \mathrm{N}$ latitude and from $125^{\circ}$ to $145^{\circ} \mathrm{E}$ longitude over the WNP during JJA and SON. The peak area of FPI-SL moves southward from approximately $24^{\circ} \mathrm{N}$ to approximately $15^{\circ} \mathrm{N}$ with a seasonal change from JJA to SON. From winter to spring, no significant FPI-SL is found over the WNP in the equatorial and subtropical regions.

Figure 2 is the same as Fig. 1, except for FPI-CR. FPI$\mathrm{CR}$ also shows significant seasonal variability. FPI-CR reaches a maximum during JJA occurring over the region along $18^{\circ} \mathrm{N}$ and a minimum during MAM. As with the FPI-SL, the peak area moves southward to the Equator from JJA to DJF. These two flow patterns are strongly related to the Asian monsoon westerly wind, as explained in section 1. Because the Asian monsoon westerly wind has a seasonal peak during the boreal summer, these flow patterns also have a seasonal peak during that time.

Figure 3 shows the horizontal distribution of FPI-EW. FPI-EW also shows significant seasonal variability and reaches a maximum during JJA and a minimum during DJF. FPI-EW is distributed in a relatively narrow region from Luzon Island in the Philippines to $8^{\circ} \mathrm{N}, 180^{\circ}$ and has a bow shape. This shape and geographical location do not largely vary with season unlike the SL and CR patterns. The frequency of TCG with an EW pattern (hereafter, TCG-EW) is most frequent during SON (Yoshida and Ishikawa 2013). There is a seasonal gap between the peak of TCG-EW and the peak of the EW 

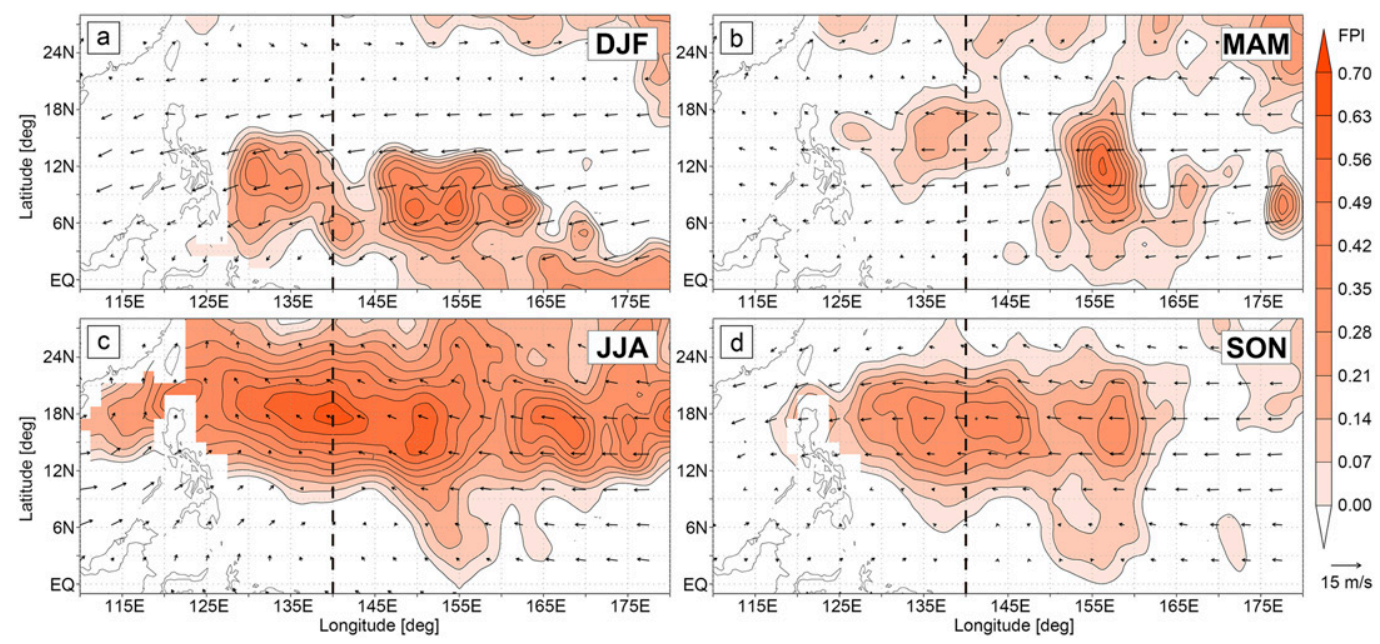

FIG. 2. As in Fig. 1, but for the CR flow pattern index.

pattern. An interpretation of this seasonal gap is that the most significant flow pattern was TCG-SL or TCG-CR during JJA rather than TCG-EW because of a strong westerly wind induced by the Asian monsoon prevailing over the easterly trade wind during the summer season. The westerly wind weakens over the WNP during autumn, and the EW pattern is more significant than that of the SL or CR.

To examine the FPI compatibility with TCG, Fig. 4 shows the TCG locations by dots superposed on the FPI horizontal distribution, in which the white dots indicate the TCG-SL, TCG-CR, and TCG-EW location in Figs. 4a, 4b, and 4c, respectively. The FPI shows the mean value for JASO from 1979 to 2016 and the dots indicate TCG locations during the same period. Because the TCG environment typically consists of multiple flow patterns (Yoshida and Ishikawa 2013), a summation of the FPIs for the three flow patterns is also shown in Fig. $4 d$ to show the mutual effect of multiple flow patterns. TCG locations are generally matched to the FPI distribution, particularly to the distribution of the FPI summation (Fig. 4d). However, the detailed fitting of the distributions to the TCG location is not perfect. Although the most frequent latitudinal TCG location is at approximately $12^{\circ} \mathrm{N}$ over the WNP, the peak for FPI-SL and FPI-CR is to the north of this area where TCG frequently occurred. The location of FPI-EW is nearer the area where TCG frequently occurred compared to that of FPI-SL and FPI-CR. This difference is a result of other environmental parameters. The relationships with the other parameters are investigated in the following section. The FPI-EW has a distinctive distribution with a
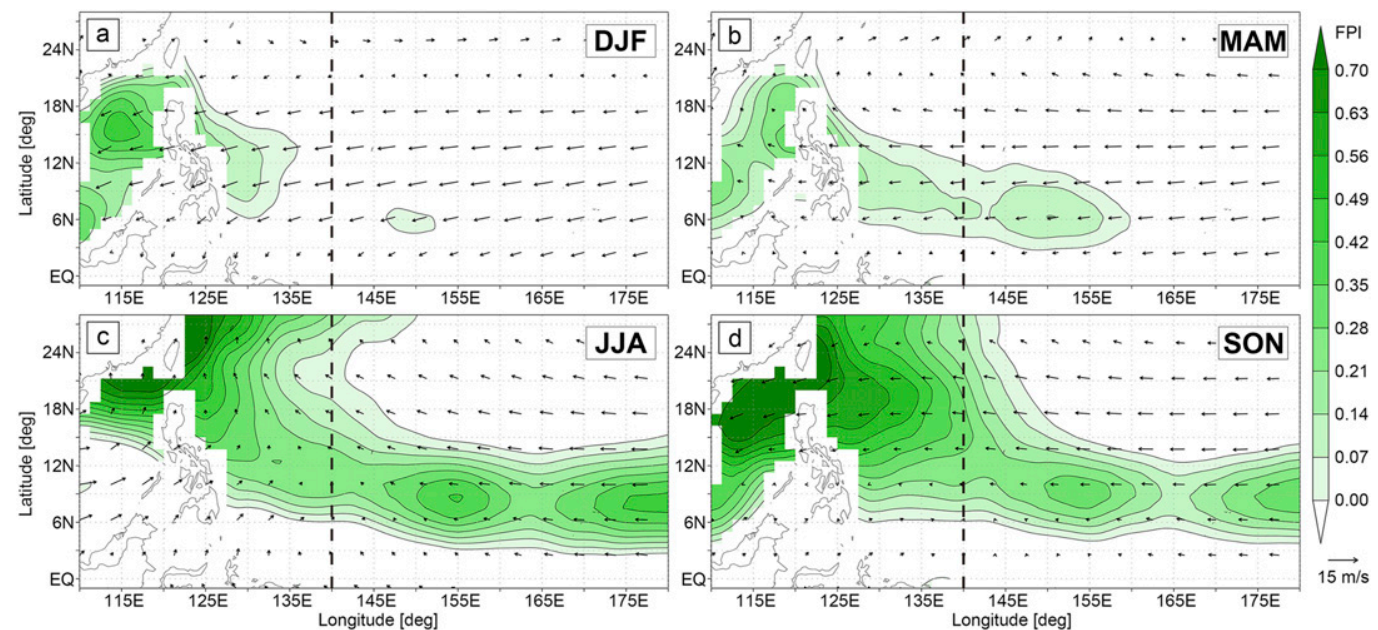

FIG. 3. As in Fig. 1, but for the EW flow pattern index. 

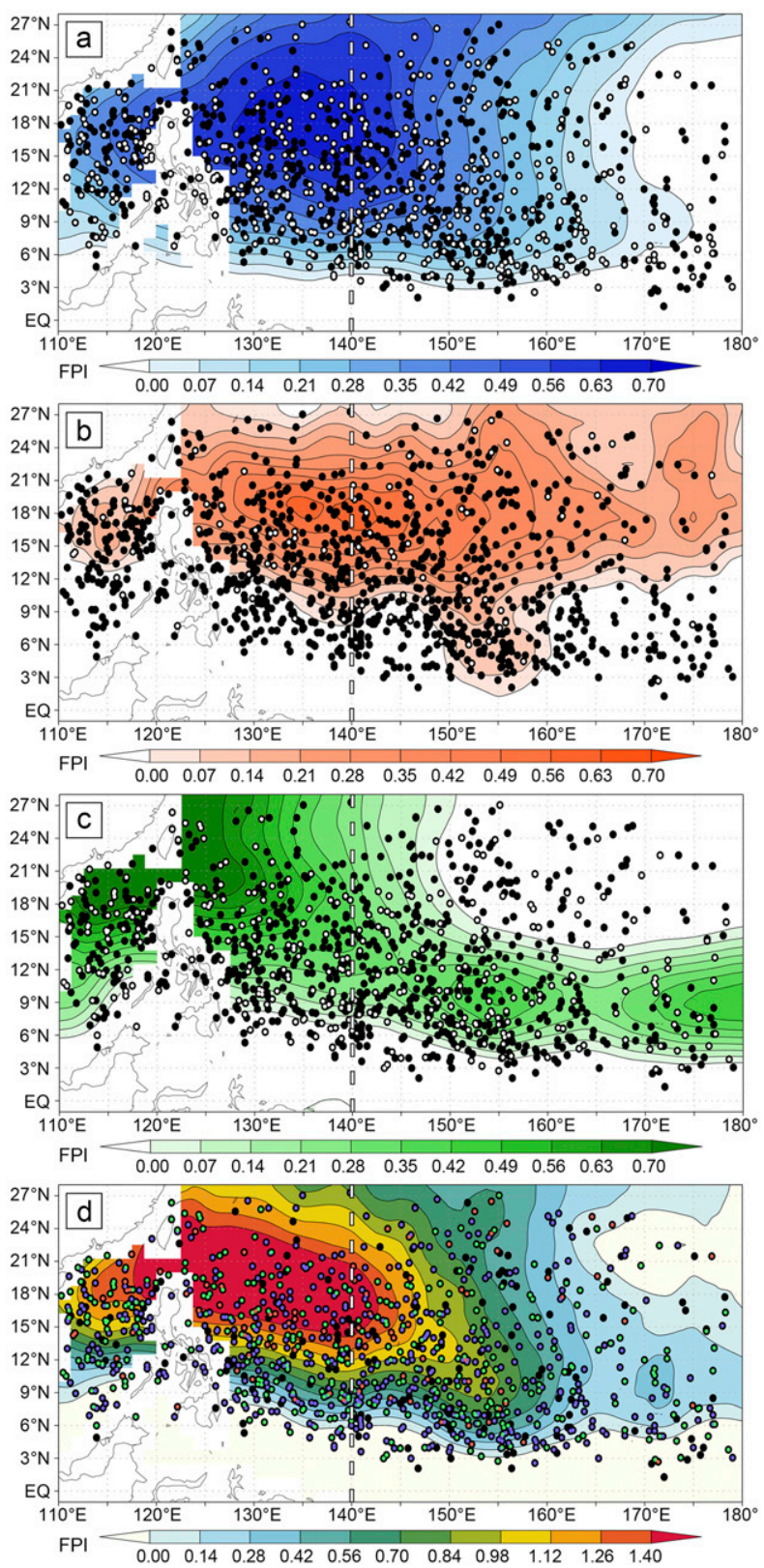

FIG. 4. Horizontal distributions of flow pattern indices during all seasons over the western North Pacific based on the mean values from 1979 to 2016 for the (a) SL, (b) CR, and (c) EW patterns, and (d) a summation of the three indices for the SL, CR, and EW patterns. The black dots show the locations of tropical cyclone genesis recorded over the period from 1979 to 2016. The white dots are the cases for the major flow patterns of SL in (a), CR in (b), and $\mathrm{EW}$ in (c). The blue, orange, and green colored dots are the major SL, CR, and EW flow patterns. The white broken lines show the location of $140^{\circ} \mathrm{E}$ longitude.

northwestward refraction at approximately $140^{\circ} \mathrm{E}$ (Fig. 4c). This distribution characteristic implies that the EW pattern can be attributed to a tropical depression type (Takayabu and Nitta 1993). The tropical depression type is a wave disturbance with a period of 3-5 days propagating westward. The pressure pattern associated with the tropical depression type is inclined toward the northwest. In addition, the tropical depression type tends to dominate over the WNP while a mixed Rossby gravity wave, which has a pressure pattern parallel to the Equator, tends to dominate over the central Pacific. According to Dunkerton (1993) and Dunkerton and Baldwin (1995), these disturbances capture a considerable fraction of lower-troposphere meridional velocity variance during the boreal summer. An additional investigation into the contribution of the tropical depression type to the environmental condition defined as the EW pattern in the current study would be required in a future work.

\section{Variations in flow patterns}

To investigate the detailed flow pattern characteristics, we established two test areas to avoid contamination because of the differences in regional variations: the west side of the WNP (western WNP: $5^{\circ}-25^{\circ} \mathrm{N}, 110^{\circ}-140^{\circ} \mathrm{E}$ ) and east side of the WNP (eastern WNP: $5^{\circ}-25^{\circ} \mathrm{N}, 140^{\circ}-$ $170^{\circ} \mathrm{E}$ ). The boundary between the western WNP and the eastern WNP is indicated by the white broken lines shown in Fig. 4.

\section{a. Seasonal variations}

The seasonal variations in each flow pattern in the two test areas are represented by the mean FPIs shown in Fig. 5. The solid and broken lines are the western WNP and eastern WNP, respectively. The correlation coefficients for the seasonal variation in TCG case numbers are listed in Table 1 and are 0.96 and 0.97 for SL-western-WNP and EW-eastern-WNP, respectively. The seasonal variation in the SL pattern is similar to that of the number of TCG cases, with the seasonal variation in the SL pattern in the western WNP being particularly close to that of the number of TCG cases. This is consistent with the fact that the SL pattern is the major pattern of TCG in the WNP (Yoshida and Ishikawa 2013). The seasonal variability in the TCG environment of low-level flow patterns is approximately represented by the SL pattern. The CR pattern is significant in both the western WNP and eastern WNP during the early summer season. In contrast, the EW pattern in the western WNP becomes significant during the late summer to autumn, which is consistent with the seasonal peak of TCG-EW.

The FPIs were compared to the other environmental parameters of TCG to determine their relationship with TCG probability. A WNP monsoon index (Wang et al. 2001) was used to evaluate the effect of monsoon 


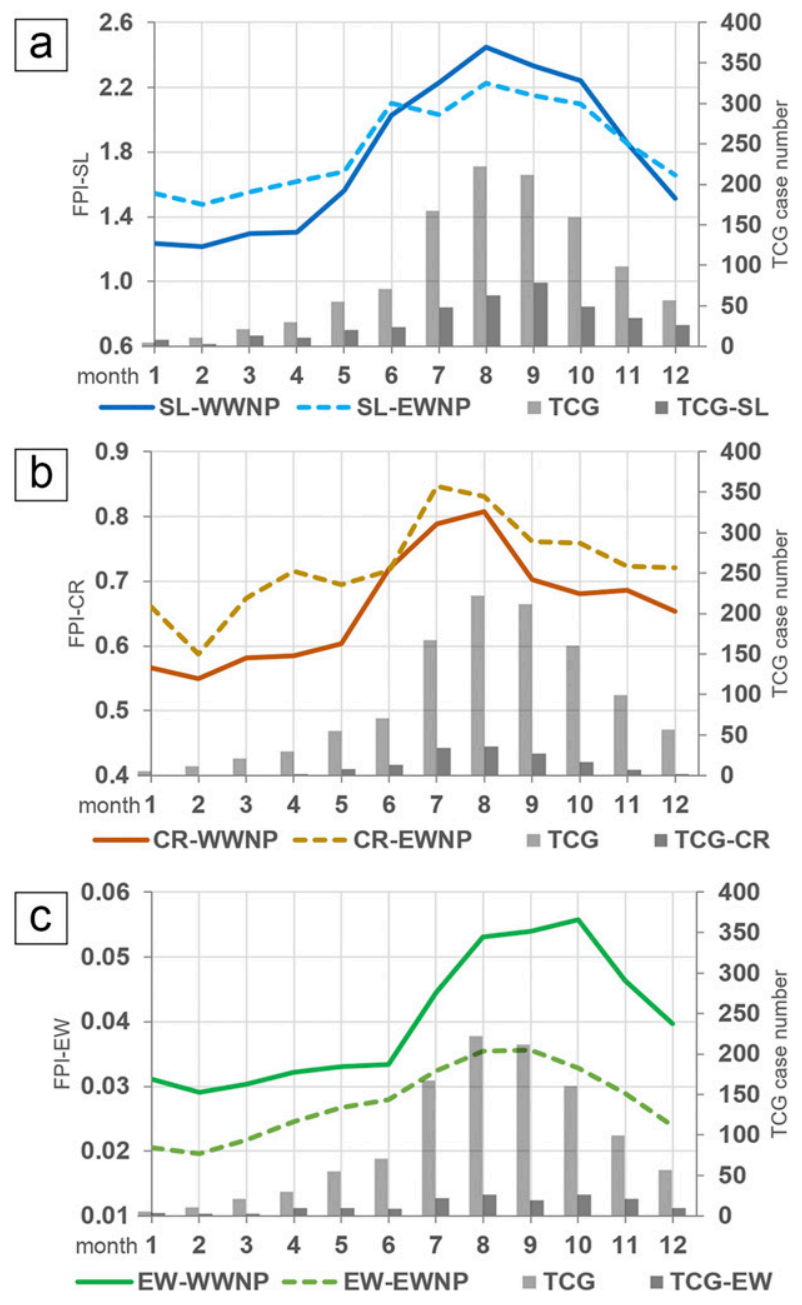

FIG. 5. Seasonal variations of flow pattern indices associated with (a) shear line, (b) confluence region, and (c) easterly wave. Each flow pattern index is the monthly mean value for the period from 1979 to 2016. The gray bars are the accumulated number of tropical cyclone genesis (TCG) cases based on the Joint Typhoon Warning Center best track data, and the dark gray bars are the accumulated number of TCG cases for each flow pattern. West side of the western North Pacific (WWNP); east side of the western North Pacific (EWNP).

activity on the TCG environment. Figure 6 shows the seasonal variability of the GPI, SST, and RH at $700 \mathrm{hPa}$ height; vertical shear of horizontal wind; and the monsoon index. The correlation coefficients between the FPIs and genesis environmental parameters are shown in Table 1 . As expected, the seasonal variation in GPI is near that of FPI-SL, and the SST is also similar to that of FPI-SL. In addition, the GPI and SST are positively correlated with the variation in the TCG cases and FPI. Meanwhile, vertical shear of horizontal wind is negatively correlated with FPIs. The correlation with RH is less significant than the correlation of
TABLE 1. Correlation coefficients for the seasonal variations in flow pattern indices and other environmental parameters.

\begin{tabular}{lrrrrrrrr}
\hline \hline & \multicolumn{3}{c}{ Western WNP } & & \multicolumn{3}{c}{ Eastern WNP } \\
\cline { 2 - 3 } & SL & CR & EW & & SL & CR & EW \\
\hline TCG & 0.96 & 0.86 & 0.93 & & 0.91 & 0.85 & 0.97 \\
GPI & 0.98 & 0.89 & 0.83 & & 0.96 & 0.87 & 0.97 \\
SST & 0.84 & 0.78 & 0.59 & & 0.94 & 0.84 & 0.94 \\
VS & -0.75 & -0.62 & -0.57 & & -0.89 & -0.73 & -0.84 \\
RH & 0.88 & 0.85 & 0.75 & & 0.96 & 0.88 & 0.98 \\
Monsoon index & 0.98 & 0.89 & 0.85 & & 0.96 & 0.85 & 0.98 \\
\hline
\end{tabular}

the other genesis environmental parameters. A decreasing FPI-CR during August seems to correspond with that of the monsoon index. The westerly winds necessary to organize the CR pattern weaken over the WNP with the decaying of the Asian summer monsoon. However, a decreasing FPI-SL is not found during August and slowly starts during September. These features suggest that the CR pattern is strongly related to the Asian monsoon and the SL pattern is not only related to the Asian monsoon but also affected by other large-scale phenomena. Temporary westerly winds induced by an intraseasonal oscillation such as the $\mathrm{MJO}$ is a possible condition to organize the SL pattern combined with trade easterly winds (Yoshida et al. 2014; Zhao et al. 2015). The MJO propagates eastward with a westerly wind over the tropical WNP, and becomes remarkable during from the boreal autumn to winter (Kemball-Cook and Wang 2001; Kikuchi et al. 2012).

\section{b. Interannual variation}

The interannual variations in the three flow patterns from 1979 to 2016 are shown in Fig. 7. The figure also shows area-averaged values over the western WNP and eastern WNP. The correlation coefficients for the interannual variation in TCG are 0.34 and 0.18 for the SLwestern-WNP and EW-eastern-WNP, respectively. The correlation coefficient for the CR pattern is less than that of the SL and EW patterns. Remarkable interannual variation can be seen in Fig. 7 for the three flow patterns. The FPI amplitudes in the western WNP differ from those in the eastern WNP, particularly for the EW pattern, while the variation in the FPI is similar among the two regions. Several peaks in the TCG variation could be explained by the FPIs. For example, the significant peaks of FPI-SL in the western WNP during 1995 and 2010 correspond with the peaks of the TCG variation during these years. A similar correspondence is found in FPI-CR in the western WNP during 1984 and 1986. Interestingly, FPI-EW shows an abrupt amplitude change during 1998 while FPI-SL and FPI-CR do not 

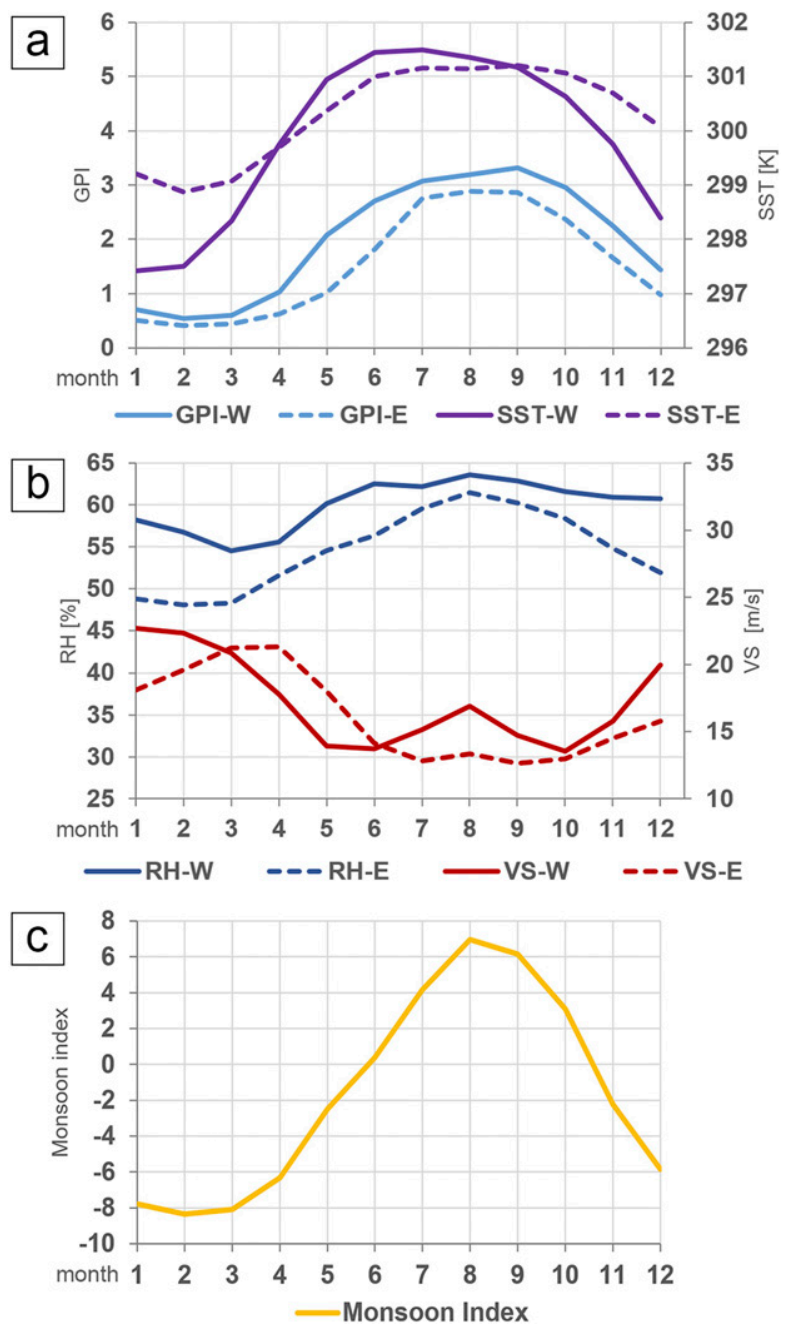

FIG. 6. Seasonal variations in general environmental parameters: (a) SST and GPI, (b) RH at $700 \mathrm{hPa}$ height and vertical shear of horizontal wind (VS) between 200 and $850 \mathrm{hPa}$ heights, and (c) western North Pacific monsoon index. The value for each variable is the monthly mean for the period from 1979 to 2016.

show a remarkable general trend during this period. The FPI-EW amplitude over the western WNP decreases after 1998. A detailed investigation of this is required in the near future.

Figure 8 shows the interannual variations in the genesis environmental parameters and Table 2 shows the correlation coefficients for the relationships between the FPIs and genesis environmental parameters. There are positive correlations for GPI and SST with the number of TCG cases, while vertical shear of horizontal wind is negatively correlated with the number of TCG cases. The same patterns are observed with regard to seasonal variability. The GPI and RH tend to be higher in the western WNP than in the eastern WNP, and FPI-EW has a similar trend to these parameters. Geographical

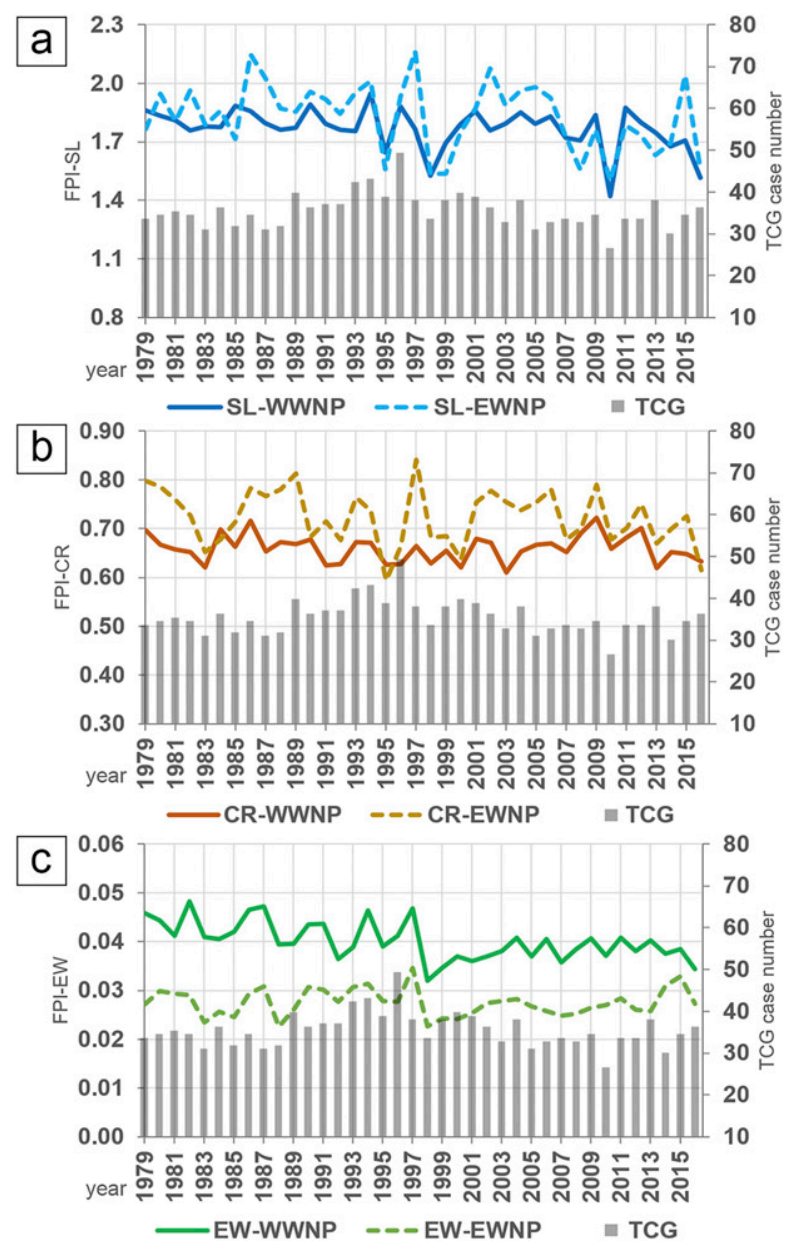

FIG. 7. Interannual variations in flow pattern indices associated with the (a) SL, (b) CR, and (c) EW patterns. The value for each index is an annual mean. The gray bars are the accumulated number of tropical cyclone genesis (TCG) cases based on the JTWC best track data. West side of the western North Pacific (WWNP); east side of the western North Pacific (EWNP).

relationships among these will be discussed in section 5 . The interannual variations are too complicated to determine any clear relationships among the flow patterns, genesis environmental parameters, and number of TCG cases. A WNP monsoon index seems to be one reasonable means to represent FPI-SL and FPI-CR. However, when FPI-SL had positive peaks during 1995 and 2010, the WNP monsoon index had negative peaks. For the positive peaks of FPI-CR during 1984 and 1986, the WNP monsoon index also has large values.

\section{Environmental conditions for TCG with flow patterns}

The FPIs were examined focusing on TCG events to determine the environmental conditions that led to 


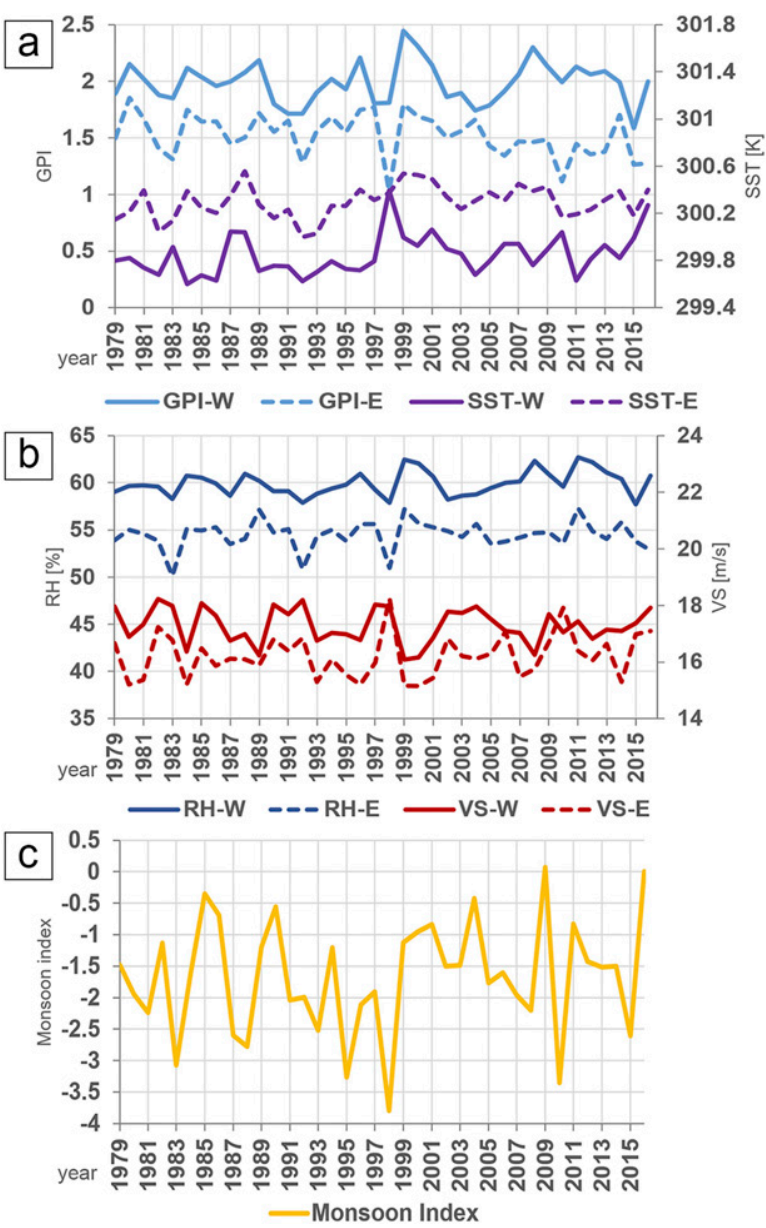

FIG. 8. Interannual variations in genesis environmental parameters: (a) GPI and SST, (b) RH at 700-hPa height and vertical shear of horizontal wind (VS) between 200 and $850 \mathrm{hPa}$ heights, and (c) western North Pacific monsoon index.

TCG. The relationships between the FPIs and TCG were investigated in terms of both temporal and spatial variations.

\section{a. Temporal variation in the FPIs within the TCG time scale}

We calculated the temporal variation in the FPIs based on the best track data. Although FPIs are originally 6-hourly data because of the input data time interval, the daily FPIs averaging four 6-hourly data periods for each date were used as described in this section. Figure 9 shows the temporal variation for each FPI from 13 days before the TCG date. The unit of the horizontal axis is days before TCG. Temporal variations in the FPIs were averaged around the TCG location in a horizontal space with several different averaging radii to provide spatial representativeness. The average radii were 400,800 , and $1200 \mathrm{~km}$ from the
TABLE 2. Correlation coefficients for the interannual variations in flow pattern indices and other environmental parameters.

\begin{tabular}{lrrrrrrrr}
\hline \hline & \multicolumn{3}{c}{ Western WNP } & & \multicolumn{3}{c}{ Eastern WNP } \\
\cline { 2 - 3 } \cline { 8 - 9 } & \multicolumn{1}{c}{ SL } & CR & EW & & SL & CR & EW \\
\hline TCG & 0.34 & -0.16 & 0.08 & & 0.23 & -0.10 & 0.18 \\
GPI & -0.58 & -0.28 & -0.50 & & -0.25 & -0.07 & -0.42 \\
SST & 0.05 & -0.12 & 0.23 & & -0.14 & -0.05 & -0.10 \\
VS & 0.08 & 0.30 & -0.15 & & 0.16 & 0.28 & 0.22 \\
RH & 0.06 & 0.21 & -0.15 & & 0.35 & 0.27 & 0.26 \\
Monsoon index & 0.47 & 0.36 & 0.16 & & 0.16 & 0.15 & 0.06 \\
\hline
\end{tabular}

mesoalpha scale to synoptic scale. The values were also averaged for the 761 TCG cases during JASO from 1979 to 2016 . The hatched area is less than 1.0 of FPI value. The three FPIs increase over time toward the genesis day (i.e., 0 days as shown in these figures). FPISL and FPI-EW rapidly increase from 3 days before TCG, with the FPI-EW increase being particularly rapid. Because these FPI values eventually exceeded 1.0 at 1 day before TCG, the flow patterns are substantially intense for TCG events compared to the FPI climatology. Meanwhile, FPI-CR tends to increase from 13 to 7 days before TCG, after which it does not change much. The FPI value only reaches 0.2 , and this is not intense comparing to the climatology. Ritchie and Holland (1999) concluded that the TCG flow pattern tends to be significant 3 days before TCG. However, it has been found in this study that the flow patterns tend to intense just one day before the genesis. As discussed in the introduction, statistics focusing only on the flow patterns has less skill to predict TCG. A large difference of temporal scale is found between SL, EW patterns, and CR pattern. FPI-SL and FPI-EW would represent the circulation of a tropical cyclone or trough. In contrast, the $\mathrm{CR}$ pattern might not be a mesoscale structure but rather a mesoscale environmental condition. The temporal variation in FPI-CR implies that the CR pattern is controlled by a largerscale phenomenon compared to that of the SL and EW patterns because a noticeable change commences in the CR pattern 10 to 13 days before TCG that is more rapid than that observed in the SL and EW patterns. The characteristics described in this section do not considerably differ with the horizontal averaging scale.

Figure 10 shows a similar temporal evolution for the genesis environmental parameters. The cross symbols show not a large value of parameters comparing to the climatological mean. The vertical vorticity at $850 \mathrm{hPa}$ has nearly the same temporal evolution as the FPIs. This is consistent with the flow patterns being recognized as a vorticity source. The GPI gradually increases with time, with a rapid increase after 3 days before TCG. The SST 


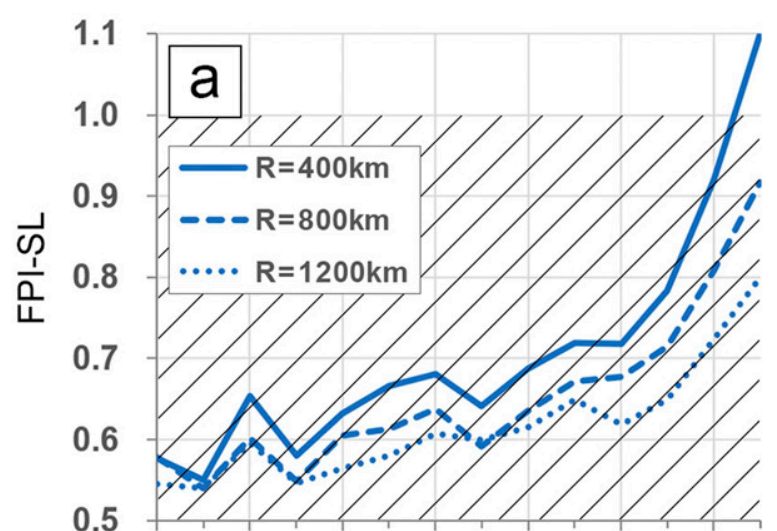

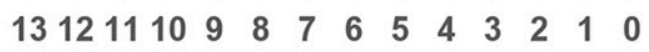

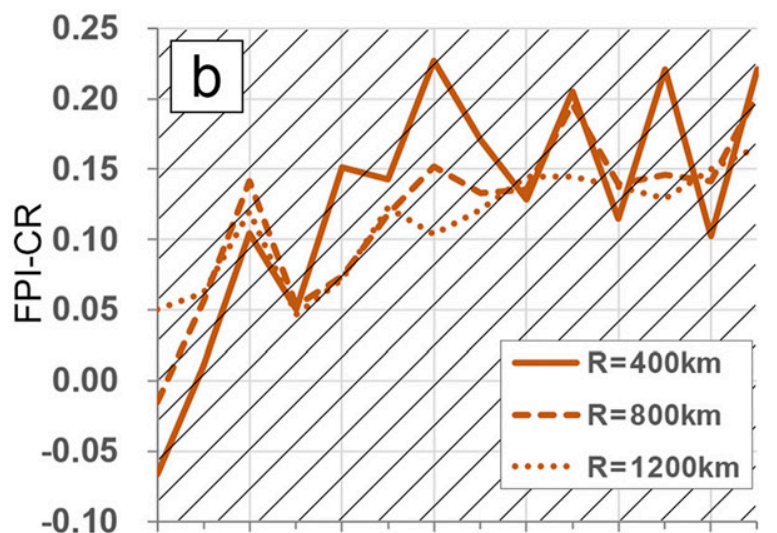

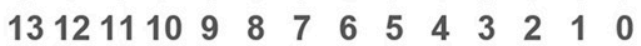

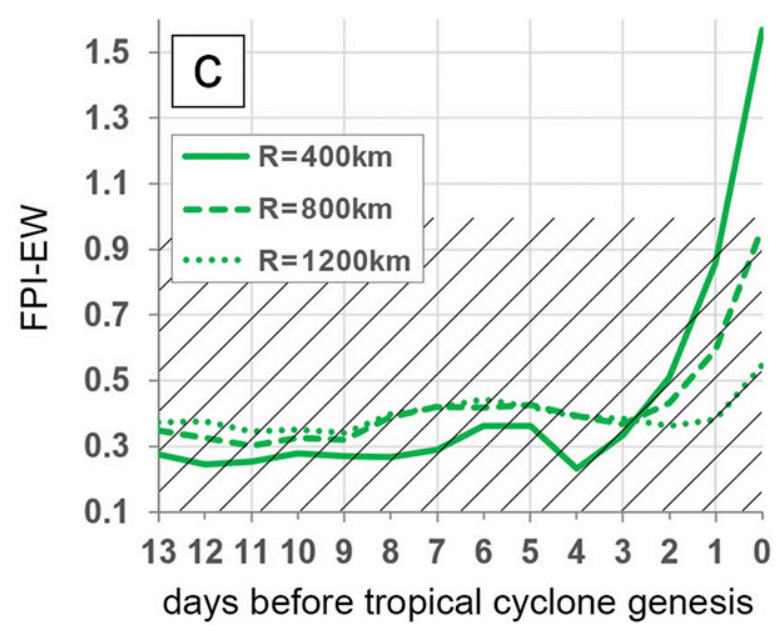

FIG. 9. Temporal evolution of the flow pattern indices associated with the (a) SL, (b) CR, and (c) EW patterns. Each flow pattern index is the average value for 761 tropical cyclone genesis cases from 1979 to 2016 during JASO. The hatch means less than 1.0 of FPI value.

and convective available potential energy (CAPE) gradually decrease. These decrease trends seem to be clear after 3 days before TCG. These changes are a result of convective activity near the TCG location. Zehr (1992)

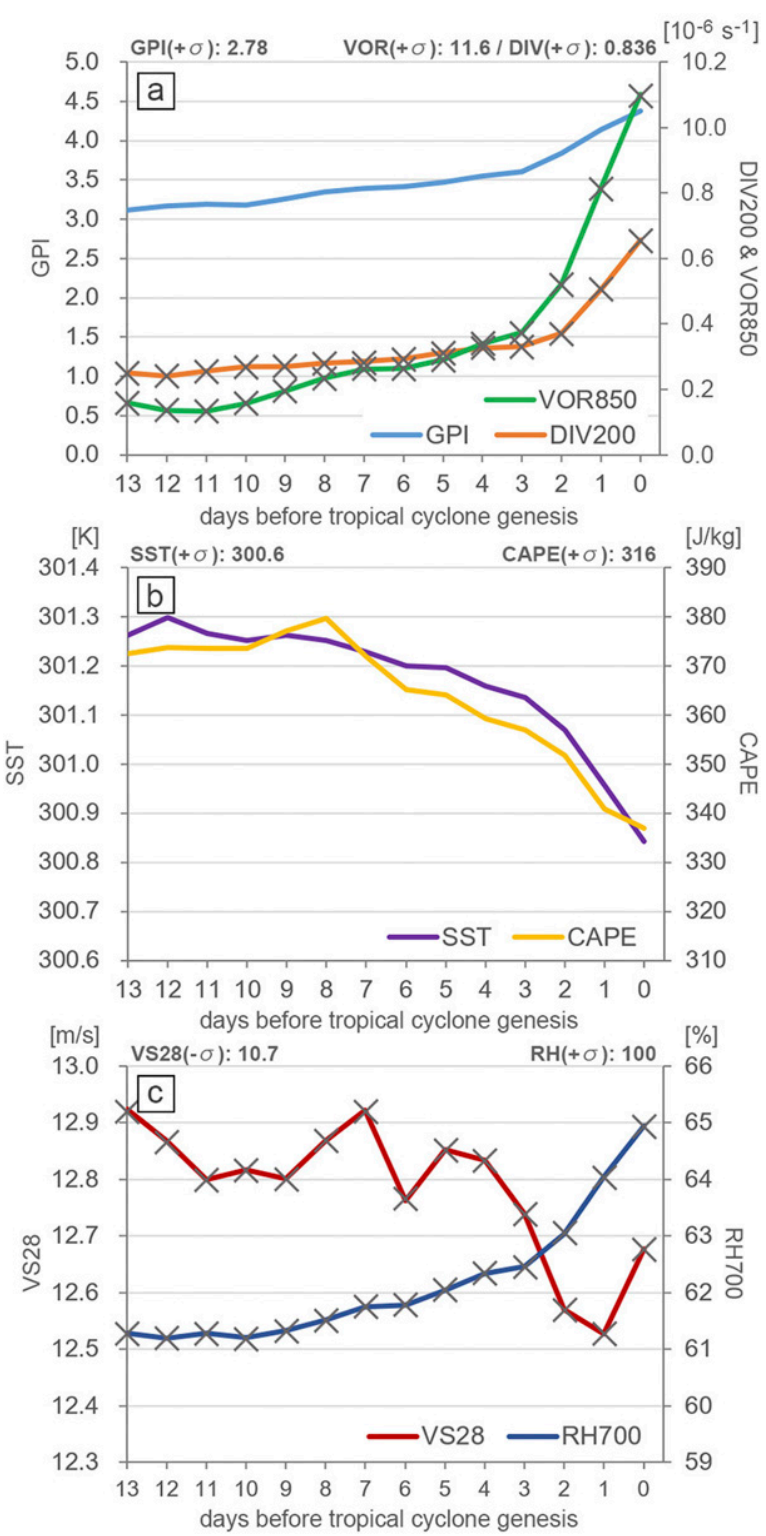

FIG. 10. Temporal evolution of genesis environmental parameters: (a) GPI and horizontal divergence at $200 \mathrm{hPa}$ (DIV200) and absolute vorticity at $850 \mathrm{hPa}$ (VOR850), (b) SST and CAPE, and (c) vertical shear of horizontal wind (VS) between 200 and $850 \mathrm{hPa}$ heights and $\mathrm{RH}$ at $700 \mathrm{hPa}$ height. Each value is the average for 761 tropical cyclone genesis cases from 1979 to 2016 during JASO. Numbers at upper corners are $1 \sigma$ value for each variable, and plus sign means less than the $1 \sigma$ value.

found that a tropical disturbance developing into a tropical cyclone tended to be significant approximately 3 days before TCG. Because the values of GPI, SST, and CAPE are exceeded $1 \sigma$ value of climatological population, these characteristics are substantially intense comparing to the climatological mean. Relative vorticity at $850 \mathrm{hPa}$, divergence at $200 \mathrm{hPa}$ and $\mathrm{RH}$ increases rapidly after 3 days before TCG, and vertical shear of horizontal wind 

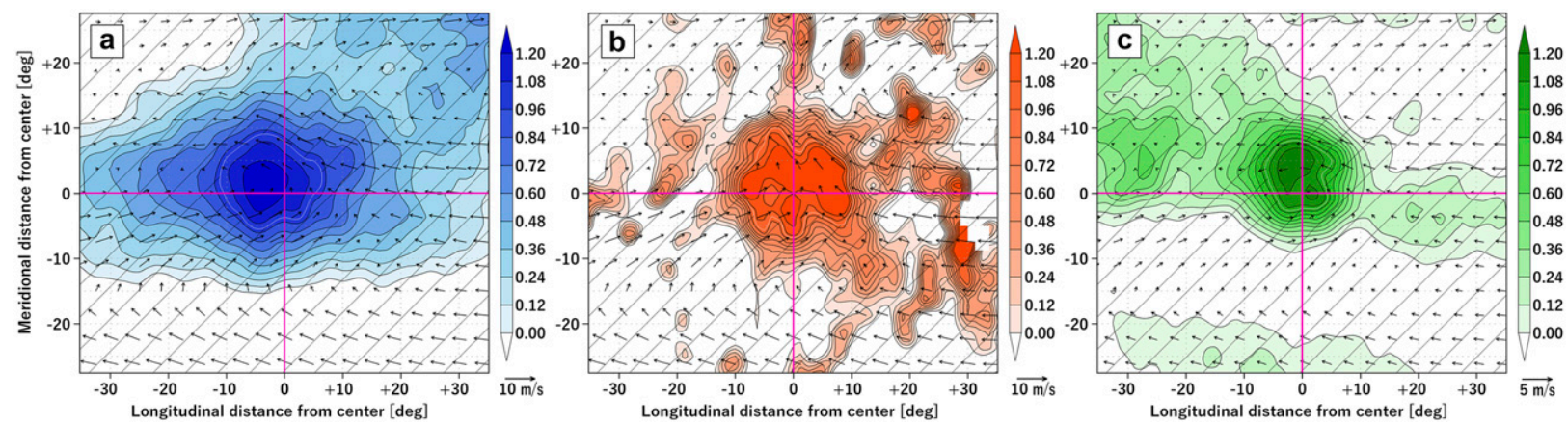

FIG. 11. Composited horizontal FPI distributions for the (a) SL, (b) CR, and (c) EW patterns for categorized tropical cyclone genesis cases during JASO from 1979 to 2016. The number of cases was 340 for the SL, 75 for the CR, and 247 for the EW patterns. The genesis location is in the center of each composite. The vectors are the composited horizontal flow at $850 \mathrm{hPa}$ height for each case. The hatched area indicates less than 1.0 of FPI value.

suddenly decreases approximately 3 to 4 days before TCG; this might be a signal of TCG initialization. However, all these trends are not remarkable comparing to the climatological mean. Furthermore, the temporal evolution of GPI is gentle in this period, and a remarkable change of evolution was not found. An understanding temporal evolution of environmental conditions from statistics is still hard even if TCG cases are categorized into flow patterns based on the circulation feature.

\section{b. Horizontal variation in the FPIs in each flow pattern}

Composite images were constructed centering on the TCG location, based on the best track data, to obtain the typical FPI horizontal distribution (Fig. 11). The FPIs were composited for cases with a major flow pattern during the JASO analysis period from 1979 to 2016. The major flow pattern for the specific TCG case was defined as the flow pattern with the largest FPI value during the 4 days before the TCG date. The area averaged FPI over a radius of $800 \mathrm{~km}$ was used for this categorization process. The number of cases was 340,75 , and 247 for the SL, CR, and EW patterns, respectively, with the daily FPI value used in the calculation. The composites for each flow pattern were constructed for each storm defined as a major flow pattern on a single day which is 4 days before the genesis day.

The FPI maximum value is near the center for every flow pattern. The FPI-SL peak is slightly shifted to the west and the FPI-EW peak is slightly shifted to the northwest of the TCG location. These horizontal peak areas had a horizontal scale of approximately $20^{\circ}$ (i.e., $2000 \mathrm{~km}$ ). Compared to the other flow patterns, FPI-SL is more widely distributed in the longitudinal direction. FPI-EW has a second peak in the northwest quadrant.
This implies the existence of a previous trough of easterly waves to the northwest. FPI-CR is more concentrated than the other flow patterns, and a remarkable cyclonic circulation is found near the center to the west of the TCG location.

The genesis environment parameters affecting TCG were superposed on these composite images as shown in Fig. 12. Because the flow patterns can extend over a broad area, as shown in Fig. 4, the composited images were nearly white if there was no cooperative organization of flow patterns with the genesis environmental parameters. The flow patterns should have some systematic correlation with the genesis environmental parameters. The GPI is elongated from the western side to the TCG location for every flow pattern. A higher GPI value is found far from the TCG location in the TCG$\mathrm{CR}$ cases. Therefore, a suitable environment for TCG is available in a larger space in the TCG-CR cases than in the TCG-SL or TCG-EW cases. The horizontal RH distributions at $700 \mathrm{hPa}$ height are also similar for every flow pattern. An elongated high RH area stretches from the western side to the center of this domain, with a slight slant in a northwest to southeast direction. At the TCG location, the southern part of the domain has a higher RH. This is a favored condition for the development and maintenance of deep convection in the cyclonic circulation around the TCG location, because the southwestern flow can convey moisture to the TCG location. The TCG location is nearly on the eastern edge of the area with a considerably high GPI and RH. There is a different horizontal distribution for vertical shear of horizontal wind compared to that of the GPI and RH. The north side in this domain had a strong vertical shear that corresponded to the midlatitudinal jet. The TCG location is in a relatively weak vertical shear area. Areas with a vertical shear of greater than $15 \mathrm{~m} \mathrm{~s}^{-1}$ are found in the southwestern quadrant in the TCG-SL and TCG-CR 

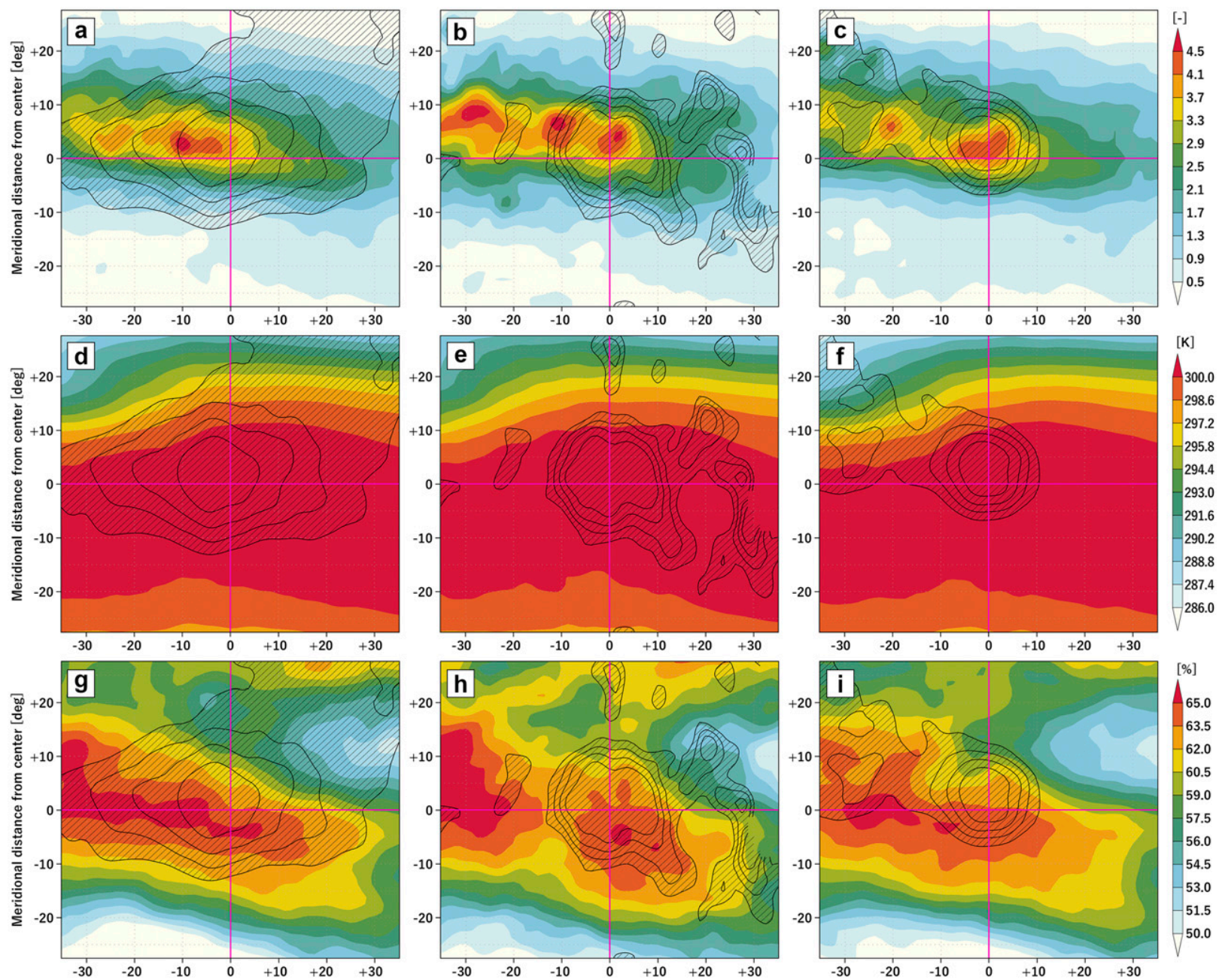

\section{\begin{tabular}{|l|}
{$[\%]$} \\
65.0 \\
63.5 \\
-62.0 \\
60.5 \\
59.0 \\
57.5 \\
56.0 \\
54.5 \\
53.0 \\
51.5 \\
50.0
\end{tabular}}
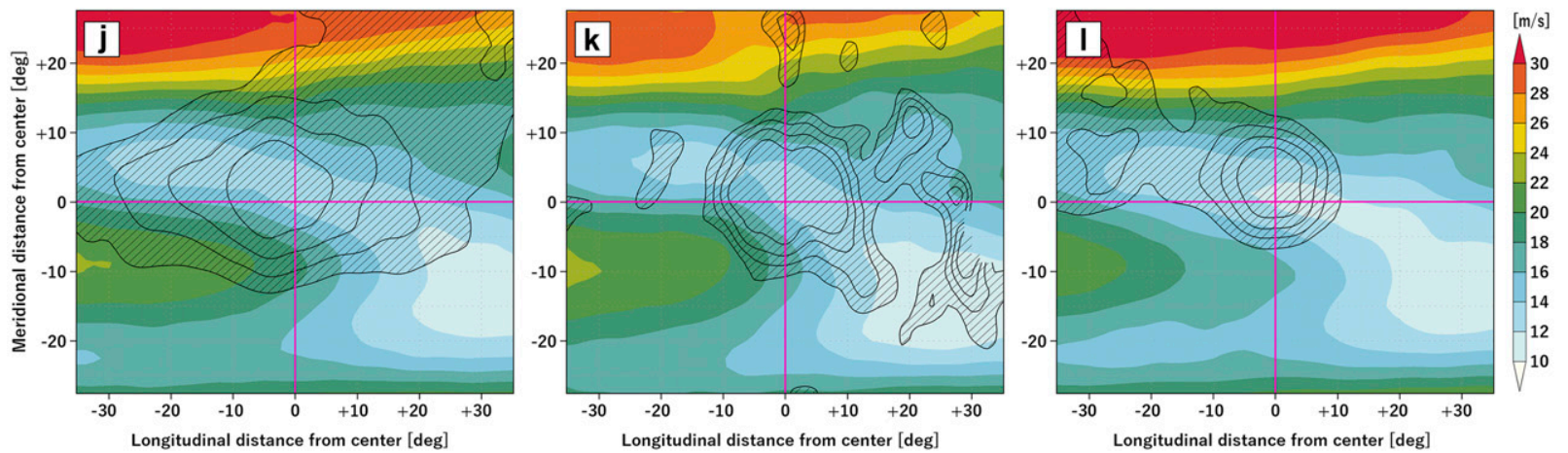

FIG. 12. Composited horizontal distributions of general environmental parameters: (a)-(c) GPI; (d)-(f) SST; (g)-(i) RH at 700-hPa height, and (j)-(l) vertical shear of horizontal wind (VS) between 200 and $850 \mathrm{hPa}$ heights. In each panel, flow pattern indices are superposed by hatched contours: (a),(d),(g),(j) SL pattern; (b),(e),(h),(k) CR pattern; and (c),(f),(i),(l) EW pattern. They were composited for categorized tropical cyclone genesis during JASO from 1979 to 2016. The number of cases was 340 for the SL, 75 for the CR, and 247 for the EW patterns. The tropical cyclone genesis location is in the center of each composite.

cases. Although a weak vertical shear is found in the southeastern quadrant regardless of the flow pattern, this area is largely not subject to TCG. This implies that TCG occurs in the gaps among strong vertical shear.
Figure 13 shows similar composite images for CAPE, with divergences at 200 and $850 \mathrm{hPa}$ heights and vertical vorticity at $850 \mathrm{hPa}$ height. The FPI distributions for every flow pattern coincide with the CAPE distribution. 

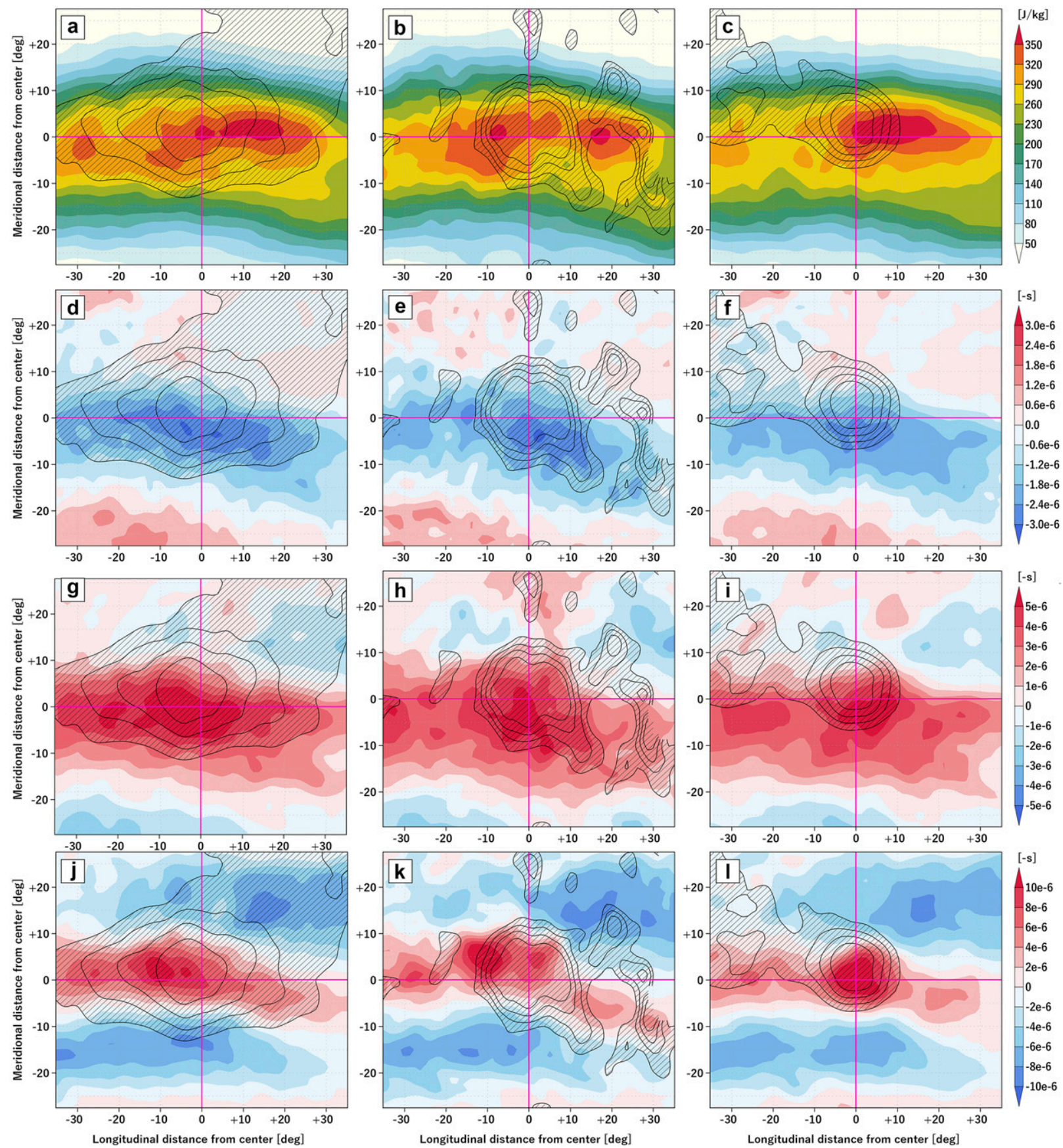

FIG. 13. As in Fig. 12, but for (a)-(c) CAPE, (d)-(f) horizontal divergence at $200 \mathrm{hPa}$ height, (g)-(i) horizontal divergence at $850 \mathrm{hPa}$ height, and (j)-(l) vertical vorticity at $850 \mathrm{hPa}$ height.

Therefore, the general characteristics of conditional instability tend to be satisfied. Divergence (convergence) is found slightly south of the composite center at $200 \mathrm{hPa}$ height $(850 \mathrm{hPa}$ height $)$. This indicates that deep convections formed and remained in this area. The vertical vorticity distributions match the flow patterns. The area with a large cyclonic vorticity in TCG-SL has a zonal line shape and the area in TCG-EW has a circular shape and is concentrated at the composite center. The area of positive vertical vorticity in TCG-CR is west of the composite center because the CR pattern is found to the east of the monsoon low.

Geographical distributions of the differences between the mean of TCG days and mean of non-TCG 

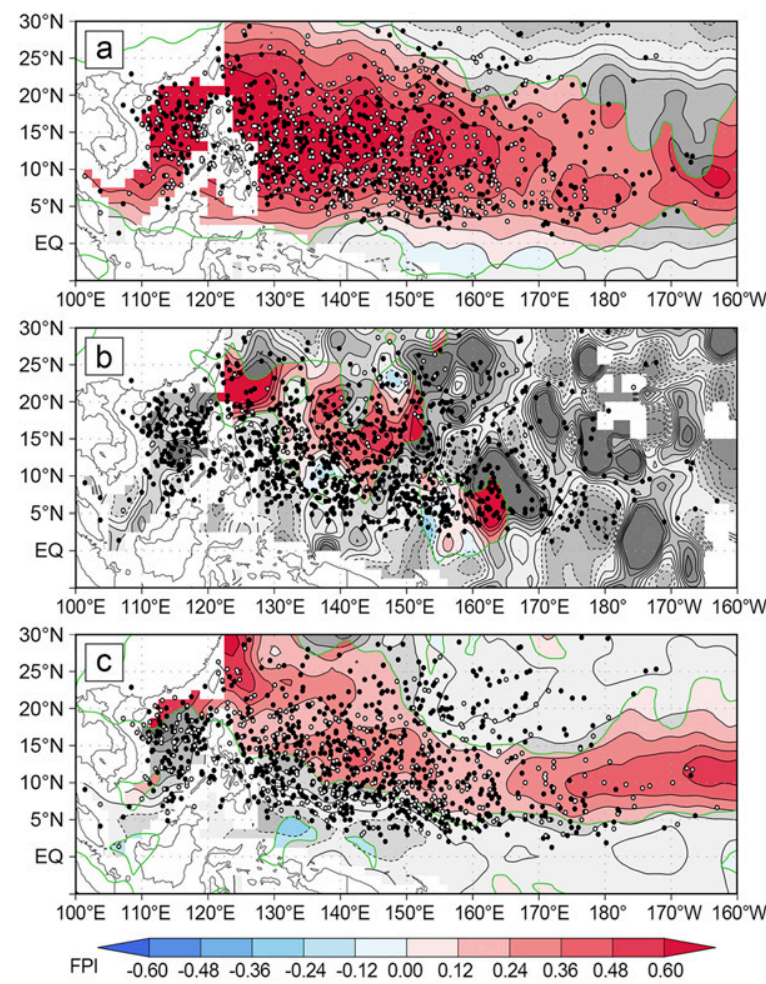

FIG. 14. Differences in the flow pattern indices between the mean of the tropical cyclone genesis days and the mean of the nongenesis days; tropical cyclone genesis mean - nongenesis mean. (a)-(c) SL, CR, and EW patterns, respectively. The difference was calculated as the 38 -yr mean for all seasons. The black dots show the locations of tropical cyclone genesis over the period from 1979 to 2016 . The white dots are the cases for the major (a) SL, (b) CR, and (c) EW flow patterns. These white dots correspond to the active period. The color shaded area is $95 \%$ significance, and the green contour indicates a boundary of the significance.

days (i.e., total days during the analysis period-TCG days) for the three flow patterns are shown in Fig. 14. Statistical $t$ test was conducted to determine a significance of the difference on each grid point, and color shaded areas indicate grid points with $95 \%$ significance from the result of the statistical test. The FPIs indicate a higher value during TCG days than that during non-TCG days. The flow patterns intensify when a tropical cyclone is developing from a tropical disturbance. The geographical distributions of the difference are approximately coincident with the distribution of the climatological mean of the FPIs shown in Fig. 4, particularly for FPI-EW. The difference in the FPI-SL is extended to the east of the date line; it seems that the westerly wind tends to prevail toward the eastern WNP in the TCG-SL cases. Although the differences in the FPI-CR are randomly distributed compared to the differences in the other flow patterns, it seems to be distributed northwestward over the WNP. This implies that the CR pattern also has a relationship with a tropical-depression-type disturbance.

To show the correspondence between the differences in the FPIs and the genesis environmental parameters, geographical distributions of the difference between the TCG cases and the climatological mean for the GPI, $\mathrm{RH}$, and vertical shear of horizontal wind are shown in Fig. 15. As same as Fig. 14, the statistical test was conducted for Fig. 15, and color shaded areas are grid points with $95 \%$ significance. The GPI tends to have a larger value than the climatological mean in the TCG cases. The RH tends to be larger at approximately $15^{\circ} \mathrm{N}$ for all of the flow patterns. Compared to the climatological mean, vertical shear of horizontal wind tends to be stronger south of the composite center and weaker north of it. FPI-CR and FPI-EW are along the boundary of a strong vertical shear region. FPI-EW especially locates over the area where the difference in vertical shear is not significant. This implies that vertical shear condition does not have a strong correlation with TCG with EW over the western part of WNP. A strong vertical shear is found when significant flow patterns are developed, but TCG occurs away from the strong vertical shear area and remains as close to the flow pattern as possible. For TCG-EW, the areas with a suitable environmental condition for TCG that have a high RH are particularly narrow (Fig. 15h). The high GPI areas are also limited and concentrated west of $140^{\circ} \mathrm{E}$ (i.e., western WNP). This is consistent with the FPI-EW and GPI having higher values in the western WNP than in the eastern WNP, which was found in the interannual variability (Figs. 7 and 9). While the EW disturbances organized along the high FPI-EW area, the probability that the disturbance develops into a tropical cyclone would be low because of unfavorable environmental conditions. This discussion might lead to the marsupial paradigm. Interestingly, the GPI distribution pattern of the TCGCR is similar to that of the FPI-CR. This suggests that a higher GPI value (i.e., a more suitable environment) is required for TCG-CR than for the other TCG cases. Furthermore, the RH for TCG-CR at a higher latitude has an approximately $2 \%$ higher value than that for the TCG cases of the SL and EW patterns. The vertical shear would be strong around the confluence region of the westerly and easterly winds. Therefore, a higher RH in TCG-CR seems to support maintenance of convection for the disturbance prevailing over the strong vertical shear. However, a tropical cyclone organized in the CR pattern has a possibility of developing into an intense cyclone supported by the high GPI. Actually, the frequency of intensification of the TCG-CR is higher 

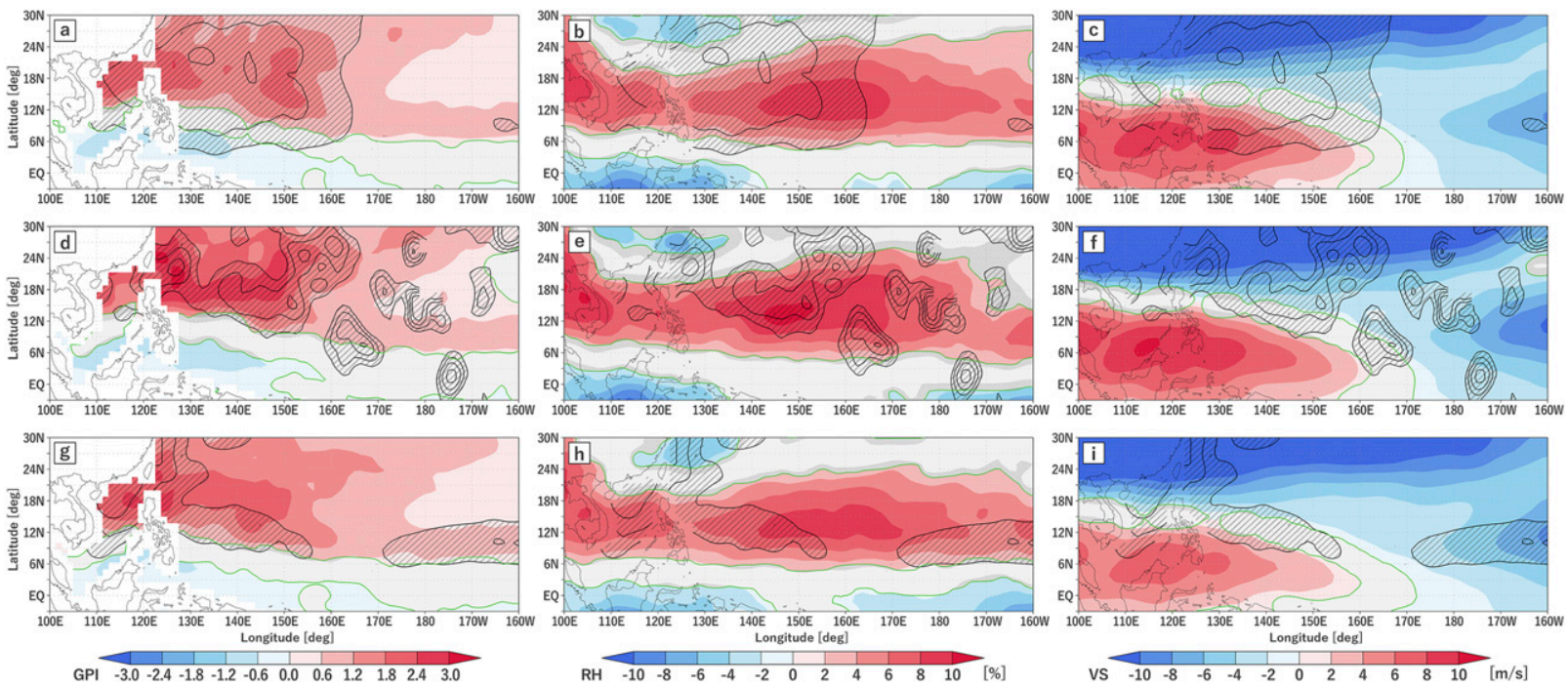

FIG. 15. Differences in the genesis environmental parameters between tropical cyclone genesis cases (active period) and the climatological mean; active period - climatological mean. The difference was calculated as the 38-yr mean for all seasons. In each panel, flow pattern indices are superposed by hatched contours: (a)-(c) tropical cyclone genesis with the SL pattern; (d)-(f) tropical cyclone genesis with the CR pattern; and (g)-(i) tropical cyclone genesis with the EW pattern. The genesis parameter in (a), (d), and (g) is the GPI; for (b), (e), and (h) it is RH; and for (c), (f), and (i) it is the vertical shear of horizontal wind between 200 and $850 \mathrm{hPa}$ heights (VS). The color shaded area is $95 \%$ significance, and the green contour indicates a boundary of the significance.

than that of the other flow patterns (Fudeyasu and Yoshida 2018).

\section{Conclusions}

The climatological characteristics of low-level flow patterns for the SL, CR, and EW, which are frequently found in TCG cases over the WNP, were investigated in this study by extending the semiobjective categorization of low-level flow patterns suggested by Yoshida and Ishikawa (2013). Grid point values of the FPIs were obtained using the extended analysis method and showed the significance of the flow patterns compared to the climatological value at the location at that time. The analysis was conducted for the period from 1979 to 2016 over the target analysis region from $110^{\circ} \mathrm{E}$ to $180^{\circ}$ longitude and from $5^{\circ}$ to $25^{\circ} \mathrm{N}$ latitude. Through this analysis, the flow pattern climatological characteristics, regardless of TCG, were identified.

It was shown that FPI-SL and FPI-CR are distributed around the area east of the Philippines. FPI-EW is broadly distributed in an east-west direction at lower latitudes. These flow patterns display seasonal variability in terms of intensity and horizontal distribution. FPI-SL and FPI-CR have a positive peak during JJA. FPI-EW has a peak during JJA in the eastern area and a peak during SON in the western area of the WNP. This seasonal variability in flow patterns is strongly correlated with genesis environmental parameters such as the
GPI, SST, RH, and vertical shear of horizontal wind. These flow patterns also show significant interannual variations. A part of the interannual variation in flow patterns seems to represent the number of TCG cases. However, the details of the relationship are not clear because the interannual variations in the flow patterns remain too complicated to be directly compared to the number of TCG cases.

Furthermore, the flow pattern temporal evolutions were investigated. All three flow patterns tend to be significant as the TCG date is reached. FPI-SL and FPIEW are significant 3 days before the TCG date. FPI-CR starts to increase 13 days before TCG and then remains stable from 7 days before TCG until the TCG date. Compared to the climatological mean, FPI-SL and FPIEW tend to be substantially intense during the TCG event, while FPI-CR is not as intense. The significance of these flow patterns was determined for the first time in this study.

The geographical relationships between the flow patterns and genesis environmental parameters were also investigated. For the TCG cases, three flow patterns are recognized in a circular area near the TCG location. The GPI and RH are also high near the flow patterns, while vertical shear of horizontal wind tends to be weak. From the perspective of geographical location, TCG occurs in areas with significant low-level flow patterns that are on the eastern edge of the high-value GPI and RH area with a weak vertical shear of horizontal wind. 
From an analysis of its temporal evolution, this favorable condition was found to gradually organize 3 days before the TCG date. Each of the conditions considered here had previously been recognized as being favorable for TCG. However, the relationships among them were investigated for the first time in this study. These findings help clarify the overall TCG process and enable development of a TCG forecasting system for the WNP.

Acknowledgments. The authors are grateful to the editor and anonymous reviewers for their useful and critical comments. The authors thank Drs. H. Ishikawa, Y. Kajikawa, Y. Miyamoto, and M. Yamaguchi for their helpful comments. Thanks also to the members of the Computational Climate Science Research Team, RIKEN Center for Computational Science, for their input. This study utilized the dataset of JRA-55 provided by the JMA and the dataset of best track produced by the JTWC. The monsoon index was downloaded from a website (http://apdrc.soest.hawaii.edu/projects/monsoon/ seasonal-monidx.html). This work is supported by MEXT KAKENHI Grants 17H02956,17K14398, and JP19H05696.

\section{REFERENCES}

Camargo, S. J., K. A. Emanuel, and A. H. Sobel, 2007: Use of a genesis potential index to diagnose ENSO effects on tropical cyclone genesis. J. Climate, 20, 4819-4834, https://doi.org/ 10.1175/JCLI4282.1.

—_, M. C. Wheeler, and A. H. Sobel, 2009: Diagnosis of the MJO modulation of tropical cyclogenesis using an empirical index. J. Atmos. Sci., 66, 3061-3074, https://doi.org/10.1175/ 2009JAS3101.1.

DeMaria, M., J. A. Knaff, and B. H. Connell, 2001: A tropical cyclone genesis parameter for the tropical Atlantic. Wea. Forecasting, 16, 219-233, https://doi.org/10.1175/1520-0434(2001) 016<0219:ATCGPF $>2.0 . \mathrm{CO} ; 2$.

Dunkerton, T. J., 1993: Observation of 3-6 day meridional wind oscillations over the tropical Pacific, 1973-1992: Vertical structure and interannual variability. J. Atmos. Sci., 50, 3292-3307, https://doi.org/10.1175/1520-0469(1993)050<3292: OODMWO $>2.0 . \mathrm{CO} ; 2$.

—_, and M. P. Baldwin, 1995: Observation of 3-6 day meridional wind oscillations over the tropical Pacific, 1973-1992: Horizontal structure and propagation. J. Atmos. Sci., 52, 1585-1601, https://doi.org/10.1175/1520-0469(1995)052<1585: OODMWO $>2.0 . \mathrm{CO} ; 2$.

—_, M. T. Montgomery, and Z. Wang, 2009: Tropical cyclogenesis in a tropical wave critical layer: Easterly waves. Atmos. Chem. Phys., 9, 5587-5646, https://doi.org/10.5194/acp-9-5587-2009.

Emanuel, K. A., 2013: Downscaling CMIP5 climate models shows increased tropical cyclone activity over the 21st century. Proc. Natl. Acad. Sci. USA, 110, 12 219-12 224, https://doi.org/10.1073/ pnas.1301293110.

—_ , and D. S. Nolan, 2004: Tropical cyclone activity and global climate. Preprints, 26th Conf. on Hurricanes and Tropical Meteorology, Miami, FL, Amer. Meteor. Soc., 10A.2, https:// ams.confex.com/ams/pdfpapers/75463.pdf.
Frank, W. M., and P. E. Roundy, 2006: The role of tropical waves in tropical cyclogenesis. Mon. Wea. Rev., 134, 2397-2417, https:// doi.org/10.1175/MWR3204.1.

Fudeyasu, H., and R. Yoshida, 2018: Western North Pacific tropical cyclone characteristics stratified by genesis environment. Mon. Wea. Rev., 146, 435-446, https://doi.org/10.1175/ MWR-D-17-0110.1.

_ , and _ 2019: Statistical analysis of the relationship between upper tropospheric cold lows and tropical cyclone genesis over the western North Pacific. J. Meteor. Soc. Japan, 97, 439-451, https://doi.org/10.2151/jmsj.2019-025.

Gray, W. M., 1968: Global view of the origin of tropical disturbances and storms. Mon. Wea. Rev., 96, 669-700, https://doi.org/10.1175/ 1520-0493(1968)096<0669:GVOTOO>2.0.CO;2.

- 1998: The formation of tropical cyclones. Meteor. Atmos. Phys., 67, 37-69, https://doi.org/10.1007/BF01277501.

Harada, Y., and Coauthors, 2016: The JRA-55 Reanalysis: Representation of atmospheric circulation and climate variability. J. Meteor. Soc. Japan, 94, 269-302, https://doi.org/10.2151/ jmsj.2016-015.

Holland, G. J., 1995: Scale interaction in the western Pacific monsoon. Meteor. Atmos. Phys., 56, 57-79, https://doi.org/10.1007/ BF01022521.

Kemball-Cook, S., and B. Wang, 2001: Equatorial waves and airsea interaction in the boreal summer intraseasonal oscillation. J. Climate, 14, 2923-2942, https://doi.org/10.1175/1520-0442(2001) 014<2923:EWAASI >2.0.CO;2.

Kikuchi, K., B. Wang, and Y. Kajikawa, 2012: Bimodal representation of the tropical intraseasonal oscillation. Climate Dyn., 38, 1989-2000, https://doi.org/10.1007/s00382-011-1159-1.

Kobayashi, S., and Coauthors, 2015: The JRA-55 Reanalysis: General specifications and basic characteristics. J. Meteor. Soc. Japan, 93, 5-48, https://doi.org/10.2151/jmsj.2015-001.

Lee, C.-S., K. K. W. Cheung, J. S. N. Hui, and R. L. Elsberry, 2008: Mesoscale features associated with tropical cyclone formations in the western North Pacific. Mon. Wea. Rev., 136, 20062022, https://doi.org/10.1175/2007MWR2267.1.

Li, T., 2006: Origin of the summertime synoptic-scale wave train in the western North Pacific. J. Atmos. Sci., 63, 1093-1102, https:// doi.org/10.1175/JAS3676.1.

— , and B. Fu, 2006: Tropical cyclogenesis associated with Rossby wave energy dispersion of a preexisting typhoon. Part I: Satellite data analyses. J. Atmos. Sci., 63, 1377-1389, https:// doi.org/10.1175/JAS3692.1.

— X. Ge, B. Wang, and Y. Zhu, 2006: Tropical cyclogenesis associated with Rossby wave energy dispersion of a preexisting typhoon. Part II: Numerical simulations. J. Atmos. Sci., 63, 1390-1409, https://doi.org/10.1175/JAS3693.1.

Madden, R. A., and P. R. Julian, 1994: Observations of the 4050-day tropical oscillation: A review. Mon. Wea. Rev., 122, 814-837, https://doi.org/10.1175/1520-0493(1994)122<0814: OOTDTO $>2.0 . \mathrm{CO} ; 2$.

Molinari, J., and D. Vollaro, 2000: Planetary and synoptic-scale influence on eastern Pacific tropical cyclogenesis. Mon. Wea. Rev., 128, 3296-3307, https://doi.org/10.1175/1520-0493(2000) 128<3296:PASSIO > 2.0.CO;2.

—, K. Lombardo, and D. Vollaro, 2007: Tropical cyclogenesis within an equatorial Rossby wave packet. J. Atmos. Sci., 64, 1301-1317, https://doi.org/10.1175/JAS3902.1.

Ritchie, E. A., and G. J. Holland, 1999: Large-scale patterns associated with tropical cyclogenesis in the western Pacific. Mon. Wea. Rev., 127, 2027-2043, https://doi.org/10.1175/1520-0493(1999) 127<2027:LSPAWT>2.0.CO;2. 
Schreck, C. J., J. Molinari, and K. I. Mohr, 2011: Attributing tropical cyclogenesis to equatorial waves in the western North Pacific. J. Atmos. Sci., 68, 195-209, https://doi.org/10.1175/ 2010JAS3396.1.

,-- , and A. Aiyyer, 2012: A global view of equatorial waves and tropical cyclogenesis. Mon. Wea. Rev., 140, 774-788, https://doi.org/10.1175/MWR-D-11-00110.1.

Schumacher, A. B., M. DeMaria, and J. A. Knaff, 2009: Objective estimation of the 24-h probability of tropical cyclone formation. Wea. Forecasting, 24, 456-471, https://doi.org/10.1175/ 2008WAF2007109.1.

Takayabu, Y. N., and T. Nitta, 1993: 3-5 day-period disturbances coupled with convection over the tropical Pacific Ocean. J. Meteor. Soc. Japan, 71, 221-246, https://doi.org/10.2151/ jmsj1965.71.2_221.

Tuleya, R. E., 1991: Sensitivity studies of tropical storm genesis using a numerical-model. Mon. Wea. Rev., 119, 721-733, https:// doi.org/10.1175/1520-0493(1991)119<0721:SSOTSG >2.0.CO;2.

Wang, B., R. Wu, and K.-M. Lau, 2001: Interannual variability of Asian summer monsoon: Contrast between the Indian and western North Pacific-East Asian monsoons. J. Climate, 14, 4073-4090, https://doi.org/10.1175/1520-0442(2001)014<4073: IVOTAS $>2.0 . \mathrm{CO} ; 2$.

Wang, Z., T. J. Dunkerton, and M. T. Montgomery, 2012: Application of the marsupial paradigm to tropical cyclone formation from northwestward-propagating disturbances. Mon. Wea. Rev., 140, 66-76, https://doi.org/10.1175/2011MWR3604.1.

, W. Li, M. S. Peng, X. Jiang, R. McTaggart-Cowan, and C. A. Davis, 2018: Predictive skill and predictability of
North Atlantic tropical cyclogenesis in different synoptic flow regimes. J. Atmos. Sci., 75, 361-378, https://doi.org/10.1175/ JAS-D-17-0094.1.

Yanai, M., 1961: A detailed analysis of typhoon formation. J. Meteor. Soc. Japan, 39, 187-214, https://doi.org/10.2151/ jmsj1923.39.4_187.

_ 1968: Evolution of a tropical disturbance in the Caribbean Sea region. J. Meteor. Soc. Japan, 46, 86-109, https://doi.org/ 10.2151/jmsj1965.46.2_86.

Yoshida, R., and H. Ishikawa, 2013: Environmental factors contributing to tropical cyclone genesis over the western North Pacific. Mon. Wea. Rev., 141, 451-467, https://doi.org/10.1175/ MWR-D-11-00309.1.

_ - Y. Kajikawa, and H. Ishikawa, 2014: Impact of boreal summer intraseasonal oscillation on environment of tropical cyclone genesis over the western North Pacific. SOLA, 10,1518, https://doi.org/10.2151/sola.2014-004.

_- Y. Yiyamoto, H. Tomita, and Y. Kajikawa, 2017: The effect of water vapor on tropical cyclone genesis: A numerical experiment of a non-developing disturbance observed in PALAU2010. J. Meteor. Soc. Japan, 95, 35-47, https://doi.org/ 10.2151/jmsj.2017-001.

Zehr, R. M., 1992: Tropical cyclogenesis in the western North Pacific. NOAA Tech. Rep. NESDIS 61, NOAA, 181 pp.

Zhao, H., R. Yoshida, and G. B. Raga, 2015: Impact of the Madden-Julian oscillation on western North Pacific tropical cyclogenesis associated with large-scale patterns. J. Appl. Meteor. Climatol., 54, 1413-1429, https://doi.org/10.1175/ JAMC-D-14-0254.1. 